\title{
Lynne Ramsey, Violist: Biography, Pedagogical Background, Teaching Techniques, and Career Advice
}

Ignacio Cuello

West Virginia University, ic0001@mix.wvu.edu

Follow this and additional works at: https://researchrepository.wvu.edu/etd

Part of the Art Education Commons, Higher Education Commons, Music Education Commons, Music Pedagogy Commons, Music Performance Commons, and the Music Practice Commons

\section{Recommended Citation}

Cuello, Ignacio, "Lynne Ramsey, Violist: Biography, Pedagogical Background, Teaching Techniques, and Career Advice" (2018). Graduate Theses, Dissertations, and Problem Reports. 3694.

https://researchrepository.wvu.edu/etd/3694

This Dissertation is protected by copyright and/or related rights. It has been brought to you by the The Research Repository @ WVU with permission from the rights-holder(s). You are free to use this Dissertation in any way that is permitted by the copyright and related rights legislation that applies to your use. For other uses you must obtain permission from the rights-holder(s) directly, unless additional rights are indicated by a Creative Commons license in the record and/ or on the work itself. This Dissertation has been accepted for inclusion in WVU Graduate Theses, Dissertations, and Problem Reports collection by an authorized administrator of The Research Repository @ WVU.

For more information, please contact researchrepository@mail.wvu.edu. 


\title{
Lynne Ramsey, Violist: \\ Biography, Pedagogical Background, Teaching Techniques, and Career Advice
}

\author{
Ignacio Cuello \\ A Research Document submitted to the \\ School of Music \\ College of Creative Arts \\ at \\ West Virginia University \\ in partial fulfillment of the requirements \\ for the degree of \\ Doctor of Musical Arts \\ in \\ Viola Performance \\ Lynn Hileman, DMA, Chair and Research Co-Advisor \\ Andrea Priester Houde, MM, GPD, Research Advisor \\ Andrew Kohn, PhD \\ Evan A. MacCarthy, PhD \\ Sergio Robles Puente, PhD
}

\section{School of Music \\ Morgantown, West Virginia \\ 2018}

Keywords: Viola, Orchestra, Classical Music, Karen Tuttle, David Dawson, Ramon Scavelli, Performance, Lynne Ramsey, Jeffrey Irvine, Robert Vernon, Cleveland Orchestra

Copyright 2018 Ignacio Cuello 


\title{
ABSTRACT \\ Lynne Ramsey, Violist: Biography, Pedagogical Background, Teaching Techniques, and Career Advice
}

\author{
Ignacio Cuello
}

This research document explores teaching methods, career advice, and major influences that shaped the professional course of the violist Lynne Ramsey. Ramsey teaches viola at the Cleveland Institute of Music and is first assistant principal viola in the Cleveland Orchestra. For over thirty years, she has taught countless viola students in the US while maintaining a full-time performance career.

The introductory chapter covers Ramsey’s biographical and educational backgrounds during her time as a student of Ramon Scavelli, David Dawson, and Karen Tuttle. It is worth mentioning that Tuttle was the primary student of one of the best-known violists in history, William Primrose. Tuttle taught Ramsey Tuttle's own interpretations of Primrose's knowledge, and consequently, Ramsey developed her own interpretations of Tuttle's knowledge. This document portrays these connections in relation to Ramsey's teaching style and expertise as a viola performer and informs my conclusions in the section dedicated to career advice. The second chapter is dedicated to Ramsey's career as a viola player and includes information about her personal preparation for orchestral auditions. The third chapter summarizes Ramsey's teaching philosophy and teaching techniques. Finally, the fourth chapter contains Ramsey's career advice for upcoming professional violists and viola teachers, including topics such as the misconception of talent and career paths. 


\section{ACKNOWLEDGMENTS}

I would like to thank my teacher and research advisor, Prof. Andrea Priester Houde, for her investment and trust in me; and Dr. Lynn Hileman, Dr. Andrew Kohn, Dr. Evan A. MacCarthy, and Dr. Sergio Robles Puente for their constant support throughout the preparation of this document. I would also like to thank Lynne Ramsey and Jeffrey Irvine for the time they spent meeting with me. Without all their help, this would have been an impossible task.

This project is dedicated to Lynne Ramsey and Jeffrey Irvine for the incredible support they gave me while I was a student at the Cleveland Institute of Music. This is also dedicated to my father, Jose Luis Cuello Rivas, my mother, María Jesús Miralvés Usón, my brother Carlos Cuello Miralvés, and my dear girlfriend, Luisa Chen for their trust and enthusiasm. The combined effort of my teachers, family, and friends made this project possible.

Thank you very much. 


\section{TABLE OF CONTENTS}

Abstract

Acknowledgments

ii

List Of Figures

iii

List Of Tables

$\mathrm{V}$

viii

Chapter 1: Lynne Ramsey's Biographical and Educational Background 1

Chapter 2: Ramsey as a Performer 18

Warm-Up Routine $\quad 20$

Practice Exercises after the Warm-Up 28

Recommendations on How to Prepare for a Successful Viola Audition 33

What to Expect in and How to Keep an Orchestral Job 35

Chapter 3: Ramsey as a Teacher $\quad 39$

Shifts in Ramsey's Teaching Styles Over Time $\quad 40$

Posture and Balance of the Instrument 41

The "Coordination" Technique 43

Body Tension Awareness $\quad 45$

Right Arm Exercises $\quad 46$

Left Hand Exercises $\quad 59$

A Guide to Phrasing 63

Chapter 4: Career Advice for the Upcoming Professional Violist 66

$\begin{array}{ll}\text { Conclusions } & 74\end{array}$

$\begin{array}{ll}\text { Bibliography } & 77\end{array}$ 


\section{LIST OF FIGURES}

Figure 1. Duquesne University's Concert Program Press Release

Pittsburgh Post-Gazette, South Hills Edition. "Going South, in Concert." February 26, 1981: 69.

Figure 2. Press Release for the Brian Young Artists Competition

Anderson, George. "Triangle Tattler: Maguire on Broadway, Townfolk."

Pittsburgh Post-Gazette. January 29, 1980: 37.

Figure 3. Ramsey Performing with Beijing Center Philharmonic

Orchestra in 1985

Photograph by the author of Ramsey’s personal copy, April 15, 2018.

Figure 4. Oberlin Conservatory of Music, Viola Faculty in 1986;

Lynne Ramsey Irvine, Viola and Orchestra Studies, Jeffrey Irvine, Viola and

\section{Chamber Music}

Photograph courtesy of the Oberlin Conservatory of Music.

Journal of the American Viola Society. "Oberlin Conservatory of Music:

Viola Faculty." Vol. 2, no. 3, November, 1986: 4

Figure 5. Ramsey's First Concert with The Cleveland Orchestra

Hall Sheet courtesy of The Cleveland Orchestra Archives. 
The Cleveland Orchestra. "From the Archives: About the Archives."

Accessed August 16, 2018.

Figure 6. Robert Vernon and Lynne Ramsey Performing the Sortomme

Concerto for Two Violas and Orchestra with The Cleveland Orchestra and

Christoph von Dohnányi, (Conductor)

Photograph courtesy of Roger Mastroianni.

Lewis, Zachary. "Cleveland Orchestra Shines Across the Board in Premiere,

Schubert's 'Great' Symphony (Review).” The Cleveland Plain Dealer.

November 20, 2015.

Figure 7. Raised Position of the Elbow during the Up-Bow Motion

Photograph by the author, April 15, 2018.

Figure 8. Lowered Position of the Elbow during the Down-Bow Motion

Photograph by the author, April 15, 2018.

Figure 9. C Major Three-Octave Scale Divided into Two Notes Per

Bow Using the "Plop and Slur" Technique

Figure 10. Placement of the Bow for Spiccato Bow-Stroke

Photograph by the author, April 15, 2018. 
Figure 11. Bowing Exercise Transcribed and Edited by Irvine

Photograph by the author, April 15, 2018, from Irvine's transcription.

Figure 12. Grouping Method Used to Improve the Bow Distribution at the Tip and Frog of the Bow

Figure 13. Body Posture while Standing

Photograph by the author, April 15, 2018

Figure 14. Playing Position while Seated

Photograph by the author, April 15, 2018.

Figure 15. Playing Position while Playing at the Frog of the Bow

Photograph by the author, April 15, 2018.

Figure 16. Playing Position while Playing in the Middle of the Bow

Photograph by the author, April 15, 2018.

Figure 17. Playing Position while Playing at the Tip of the Bow

Photograph by the author, April 15, 2018

Figure 18. Lowered Position of the Right-Wrist and Hand Prior

to Up-Bow Martelé Bow-Stroke 
Photograph by the author, April 15, 2018.

Figure 19. Contour of the Bow while Adding the Use of Circular

Motion for a Smooth Bow-Change

Figure 20. Three-Step Vibrato Exercise Recommended by Ramsey

LIST OF TABLES

Table 1. Exercise to Practice the Martelé Bow-Stroke on a Three-Octave Scale

$25-26$

Table 2. "Sheet of Emotions" Prepared by Tuttle and Taught by Ramsey 


\section{CHAPTER 1}

\section{LYNNE RAMSEY'S BIOGRAPHICAL AND EDUCATIONAL BACKGROUND}

Lynne Ramsey has dedicated her entire life to the viola and to the members of the violaplaying community, and her contributions deserve to be explored and discussed among violists and other musicians. Throughout this document, I discuss Ramsey's career as an artist and teacher from several standpoints to offer a complete vision of her musical career. To fully understand Ramsey's importance in the viola community, it is crucial to point out teacher Karen Tuttle's contributions to Ramsey's viola playing. Tuttle was a highly praised student of one of the most influential viola soloists of the $20^{\text {th }}$ century, William Primrose. After studying Primrose's main viola techniques, Tuttle distilled them, and by combining them with other techniques learned from influential artists such as cellist Pablo Casals, she developed a successful viola teaching method that is now taught worldwide. Some of the techniques and exercises that Ramsey learned as a student of Tuttle included breathing exercises, which have helped her to release unwanted muscular tension while playing, and the "Coordination" technique, which enabled her to synchronize the right arm and left hand naturally. Tuttle also taught Ramsey to emulate feelings such as "joy" or "anger" while playing with the aid of Tuttle's "Sheet of Emotions" device. I discuss these and other essential concepts taught and performed by Ramsey in the second and third chapters of this document.

My first chapter provides details related to Ramsey's musical mentors and professional highlights as a viola performer and teacher. By describing these events, I hope to demonstrate Ramsey's relevance in the viola community. Throughout her career as a teacher, she has encouraged many generations of violists and has helped them to find and follow their goals as 
performers and teachers. Some of the music schools in which she has taught include the Oberlin Conservatory, Duquesne University's Mary Pappert School of Music, and the Cleveland Institute of Music. As a performer, she has served as principal violist with major orchestras such as Rochester Philharmonic Orchestra, and the Saint Paul Chamber, and she currently serves as assistant principal viola with the Cleveland Orchestra. As a chamber musician, she has collaborated with several successful ensembles throughout her career, producing a wide array of well-regarded albums. Finally, as a soloist, Ramsey has collaborated with renowned orchestras such as the Beijing Center Philharmonic Orchestra, the Saint Paul Chamber Orchestra, the North Carolina Symphony, and of course, the Cleveland Orchestra.

In interviews, Ramsey has said that she showed a great interest in music from a young age. ${ }^{1}$ Ramsey was born in 1954 and was introduced to music as a child by her mother, who played the piano. When Ramsey turned four, her mother started teaching her piano at home. Because her father worked in the Navy, the entire family moved every two years. By the time she was seven years old, Ramsey's family had moved to Hong Kong, where her parents took her to a concert played by the Hong Kong Philharmonic. Ramsey showed interest in the orchestra, leading to her first contact with the violin. She started taking private violin lessons with the concertmaster of the orchestra, Arrigo Foa $(1900-1981){ }^{2}$ However, the relationship between Foa and Ramsey was challenging from the very beginning. He was very strict with his students, an approach Ramsey found off-putting, so instead of practicing, she spent her practice time reading books.

\footnotetext{
${ }^{1}$ Lynne Ramsey, interview with the author, Cleveland, April 2018. (Hereafter "Ramsey interview.")

${ }^{2}$ Xu Buzeng, "Jews and The Musical Life of Shanghai," in The Jews of China, vol. 1, ed. Jonathan Goldstein (Armonk, NY: M. E. Sharp Inc., 1999), 230-231.
} 
When Ramsey was ten years old, her family moved to Orange County, California, where she joined the elementary school orchestra, first as a violinist. Since the orchestra lacked viola players, she switched from violin to viola. Her mother often invited other music students into their house for chamber music gatherings, which led not only to improvement in Ramsey's sightreading skills, but also encouraged her to increase her practice time. At the age of fifteen, after several other moves, Ramsey's family moved to Washington DC, where she met her first viola mentor, Ramon Scavelli (b. 1935). Scavelli served as a section viola player with the National Symphony Orchestra for over thirty years and, in his retirement from the NSO, still performs in ensembles such as the Fairfax Symphony Orchestra, teaches viola privately, and works as a professional photographer. ${ }^{3}$

Ramsey's lessons with Scavelli could last up to two hours, and Scavelli's detail-oriented work always aimed for the perfect performance. Ramsey was not used to such structured lessons and practice, but, respecting Scavelli more than she had Foa, she continued studying with him over a period of three years. Scavelli's disciplined and methodical teaching approach allowed Ramsey to learn and revisit all forty-two etudes composed by Rodolphe Kreutzer $(1766$ - 1831) three times; several of the technical exercises prepared by Otakar Ševčík (1852 - 1934); scales; and concert pieces including Georg Philipp Telemann, Carl Stamitz, and Ivan Khandoshkin's viola concertos and Ernest Bloch's Suite B. 41, (1919). Scavelli always demanded the highest level of performance during her lessons, which forced Ramsey to improve her playing. She learned to emulate Scavelli's playing, which she described as always pleasant to listen to and clear: "[he had a] beautiful sound, but he also never let anything go by." ${ }^{4}$ Most importantly to Ramsey, the greatest gift she received from Scavelli was his enduring faith in her. He told her

\footnotetext{
${ }^{3}$ Ramon Scavelli, interview with the author, May 2018.

${ }^{4}$ Ramsey interview.
} 
that she could be whatever she wanted to be, so if she wanted to become a viola player in a big orchestra, she could do it. In the 1960s, there were only a few women in the U.S. who held positions in major symphony orchestras, but that did not affect Ramsey's career decisions. Soon after Ramsey started studying with Scavelli, she began collaborating with different ensembles around the Washington area such as the Northern Virginia Youth Symphony, the Fairfax Symphony, and the Arlington Symphony. These experiences, in addition to her time with Scavelli, were vital for Ramsey's musical career, and she decided to become an orchestral player while being his student. What attracted her the most to orchestral playing was the symphonic repertoire, the blend and dynamic possibilities of the orchestra, and being able to experience it all while seated in the center of the group. ${ }^{5}$

While playing with the Washington-area symphony orchestras listed above, Ramsey started receiving performing awards, including acceptance to the American Youth Performs program. American Youth Performs allowed music students to perform in small ensembles throughout the US, culminating the series with a final concert in New York's Carnegie Hall broadcasted nationwide. There, Ramsey met musicians that now hold recognized positions in orchestras and colleges: Richard Weiss (Assistant Principal Cello of the Cleveland Orchestra), Steven Tenenbom (Viola Faculty at the Julliard School of Music), and Karen Ritscher (Viola Faculty at the Manhattan School of Music). ${ }^{6}$ American Youth Performs connected Ramsey with the Boston University Tanglewood Institute, where she studied with the Polish violinist, Roman Totenberg (1911 - 2012), in the Young Artist High School Program. During this program she also met the violist, Steve Ansell, who would eventually lead Ramsey to her most influential mentor, Karen Tuttle (1920 - 2010). After two consecutive summers attending the young artist

\footnotetext{
${ }^{5}$ Ramsey interview.

6 Ibid.
} 
program at Tanglewood, Ramsey was invited to be a part of the fellowship program, performing as a member of the festival orchestra and in several chamber groups. By playing in the professional orchestra, she learned the importance of teamwork in a large ensemble. ${ }^{7}$

Ramon Scavelli's influence is undoubtedly one reason why Ramsey was so successful at such a young age. Scavelli's approach with Ramsey was simple and professionally-oriented: during Ramsey's lessons he focused on consistent intonation, a healthy sound, and accurate rhythm. The overall level of viola playing when Ramsey was growing up was not as competitive as it is nowadays, which Ramsey attributes to the fact that some of the upcoming viola players during her youth were former violinists who did not excel on their previous instrument. ${ }^{8}$ While Ramsey was also a former violinist, her education with Scavelli and dexterity as a violist set her apart from the rest of the students.

By the time Ramsey finished high school, she had studied with Scavelli for three years, and she decided to find a college professor who would help her continue growing as a viola performer. She auditioned for the University of Michigan (Ann Arbor), University of Southern California (Los Angeles), and Indiana University (IU) (Bloomington) and ultimately decided to pursue her college degree at IU, where she would study with the violist David Dawson (1913 1975). Dawson had previously played as a section violist with the Metropolitan Opera Orchestra, Minneapolis, and NBC Symphony Orchestras, and was a founding member of the Berkshire String Quartet at IU. ${ }^{9}$

Dawson taught Ramsey the importance of being self-critical to achieve a unique viola sound. He also taught her about musical integrity, which contributed to her belief in herself. He

\footnotetext{
${ }^{7}$ Ramsey interview.

${ }^{8}$ Ibid.

${ }^{9}$ Fritz Magg, "Bloomington Faculty Council Minutes: Memorial Resolution for David P. Dawson", Indiana University, April 6, 1976, accessed August 9, 2018, http://webapp1.dlib.indiana.edu/bfc/view?docId=B34-1976.
} 
stated that every player had to have the same dedication as the principal players: he himself had served in the back of the viola section of the Minnesota Orchestra with distinction and dedication. This attitude helped Ramsey to respect herself as a musician throughout her career. At IU, Ramsey also collaborated with ensembles within the institution, joining several opera productions, symphonic programs, and chamber music groups. As a freelancer, she played for opera and gospel productions and in recording sessions.

However, Ramsey struggled with Dawson from the beginning of her studies at IU. After finishing her freshmen year at IU, she transferred to the Julliard School of Music, where she studied with William Lincer (1907 -1997). Lincer was a successful performer who had premiered pieces by Frank Bridge and served as principal violist with the Cleveland Orchestra and the New York Philharmonic. ${ }^{10}$ Lincer was also part of the Jacques Gordon String Quartet.

Lincer described his teaching method as "an innovative and comprehensive approach to teaching the performing arts." 11 His method aimed to improve the emotional connection the performer had with the music through techniques such as breathing, relaxation, and visualization studies. (A lengthier explanation of Lincer's teaching methodology can be found in John Jake Kella's dissertation “The Development and Qualitative Evaluation of a Comprehensive Music Curriculum for Viola, with an Historical Survey of Violin and Viola Instructional Literature from the $16^{\text {th }}$ Through $20^{\text {th }}$ Centuries, Including a Review of the Teaching Concepts of William Lincer." ${ }^{12}$ ) In addition to taking lessons from Lincer, Ramsey improved as a violist by listening and imitating music recordings such as the Bartok Viola Concerto as performed by William

\footnotetext{
10 The William Lincer Foundation, “William Lincer’s Biography,” accessed August 9, 2018, http://www.williamlincer.org/bio.htm.

${ }^{11}$ Ibid.

12 John Jake Kella, "The Development and Qualitative Evaluation of a Comprehensive Music Curriculum for Viola, with an Historical Survey of Violin and Viola Instructional Literature from the $16^{\text {th }}$ Through $20^{\text {th }}$ Centuries, Including a Review of the Teaching Concepts of William Lincer," (PhD dissertation, New York University, 1983), 532-588.
} 
Primrose, a work she eventually performed with the Juilliard Symphony Orchestra as a winner of the school's concerto competition. ${ }^{13}$

After finishing her undergraduate and master's studies at the Julliard School at age 21, Ramsey obtained her first full time orchestra job with the Pittsburgh Symphony Orchestra. She served as part of the Pittsburgh Symphony viola section for nine years, between 1975 and 1984, and as part of the viola faculty at Duquesne University. In addition to her responsibilities as an orchestra member and teacher, Ramsey also collaborated in smaller ensembles with faculty and students of Duquesne University. ${ }^{14}$ (See Figure 1.)

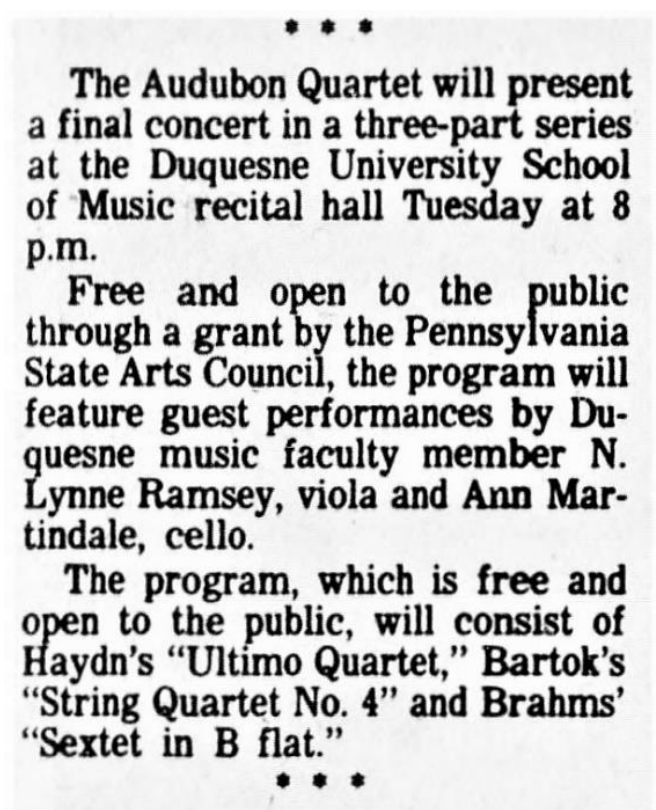

Figure 1. Duquesne University's Concert Program Press Release

\footnotetext{
${ }^{13}$ Ramsey interview.

14 "Chamber Music at Heinz Hall, Performance with members of the Pittsburgh Symphony," Pittsburgh Post-

Gazette, Weekend Section, November 16, 1984: 4, https://search-proquest-

com.www.libproxy.wvu.edu/hnppittsburghpostgazette/docview/1860069916/CB88B5BC34CF4DF8PQ/2?accountid $=2837$.
} 
While in Pittsburgh, Ramsey decided to revisit her approach to viola playing. She was twenty-four years old when violist Steve Ansell (current Principal viola of the Boston Symphony Orchestra), traveled to Pittsburgh for a performance, which Ramsey attended. She had known Ansell from the Young Artists Performs, but his approach to viola performance had changed radically after studying with Karen Tuttle at the Curtis Institute of Music in Philadelphia. Ansell's breakthrough as a violist inspired Ramsey profoundly, which motivated her to contact Tuttle and take private lessons for two years.

Tuttle (1920-2010) studied with legendary artists such as William Primrose, Pablo Casals, and Alexander Schneider. Mentors such as Primrose taught by example, and Tuttle acquired knowledge from him through close observation. When Tuttle transferred this wisdom into words she created her own viola teaching method, which is today taught by violists around the world. In addition to her successful teaching career, Tuttle also thrived as a performer, being the first woman to serve as a violist with the NBC Symphony Orchestra. ${ }^{15}$

Several research documents discuss Tuttle's teaching methodology, including studies by Lauren Burns and Susan Dubois. ${ }^{16}$ Here I want to focus on Ramsey's personal interpretation of Tuttle's teaching. In Ramsey's words, Tuttle was a teacher who "always found that special nugget or kernel in each player, and after she found that, she figured out a way for that to come out and express itself that was uniquely to each player." ${ }^{17}$ One example of this, Tuttle's method of teaching based on the physical characteristics of individual violists, is cited by Burns: "players with short arms must reach the shoulder blade forward for the last few inches of bow, and they

\footnotetext{
${ }^{15}$ Emmanuella Reiter-Bootiman, “Karen Tuttle, 1920 - 2010," The Strad Magazine, vol. 122, issue 1451: 30-31, http://search.ebscohost.com.www.libproxy.wvu.edu/login.aspx?direct=true $\& d b=f 5 h \& A N=58042278 \&$ site $=$ ehostlive.

${ }^{16}$ Burns, "Coordinated Action in String Playing: A Comparative Study of the Teachings of Paul Rolland and Karen Tuttle"; Dubois, "Current Methods and Techniques in College-Level Viola Pedagogy," 175-190.

${ }^{17}$ Ramsey interview.
} 
might not be able to reach the tip at all. Players with long arms might have trouble when approaching the frog, needing to raise the wrist and focus on staying open across the collarbone." 18 Although Ramsey already had a strong technique foundation before she started studying with Tuttle, Tuttle taught her more clearly how every person is physiologically and mentally different and has different goals and qualities, all of which require a personalized approach. According to Ramsey, Tuttle offered her a set of tools that simplified her right-arm and left-hand technique. For instance, Ramsey learned that every bow-stroke is originated from the on-the-string stroke called détaché. This helped her simplify her right-arm technique. The left-hand technique was based on three premises: "naturalness, ease, and impulse."19 Tuttle taught this without the aid of the viola. First, the motion of each left-hand finger should start from the base knuckle, and then it should drop its weight on the palm. Continuing this motion, the weight of the finger should release back independently. The goal of this technique without the viola is to familiarize the hand with this motion, and then to put it into practice with the viola. ${ }^{20}$ In addition to these right-hand and left-hand techniques, Ramsey also learned about body awareness. She learned to create an open body stance with wide shoulders and upright torso while playing, which improved her playing and confidence on stage. ${ }^{21}$

\footnotetext{
${ }^{18}$ Burns, "Coordinated Action," 58.

${ }^{19}$ Ramsey interview.

${ }^{20}$ Ibid., 62.

${ }^{21}$ Ramsey interview.
} 
Ramsey continued to receive awards as a soloist while studying with Tuttle. In 1980, after her first year as Tuttle's private student, Ramsey received the "Musicians Union Award" from her performance at first Lionel Tertis Viola Competition. The first and second prizes were received by top viola players, Paul Neubauer and Kim Kashkashian. ${ }^{22}$ That same year, Ramsey placed second in the Brian Young Artist Competition, which offered Ramsey the opportunity to perform the Béla Bartók Viola Concerto with the North Carolina Symphony Orchestra. ${ }^{23}$ (See

Figure 2.)

\section{Lynne Ramsey, a member of the Pittsburgh Symphony viola section since 1976 , placed sec- ond in the Brian Young Artists' Competition for strings in Raleigh, N.C. She's the first violist ever to reach the finals of this prestigious com- petition.}

Figure 2. Press Release for the Brian Young Artists Competition

In 1980, after attending the Aspen Music Festival as preparation for the Tertis Competition, Ramsey was invited to join the faculty of the festival and taught there in 1981, from $1983-1989$, and from $2004-2011 .{ }^{24}$ As a faculty member, Ramsey often collaborated in chamber music recitals and as a soloist, performing Berlioz's Harold in Italy with the Aspen Concert Orchestra in $1986 .{ }^{25}$

\footnotetext{
${ }^{22}$ Maurice W. Riley, The History of the Viola, 2nd ed. (Ann Arbor, MI: Braun-Brumfield, 1991), 258-259.

${ }^{23}$ Anderson, George, "Triangle Tattler: Maguire on Broadway, Townfolk," Pittsburgh Post-Gazette, January 29, 1980: 37, https://search-proquest-com.www.libproxy.wvu.edu/docview/1859679924? accountid=2837.

${ }^{24}$ Ramsey interview.

${ }^{25}$ Hector Berlioz, Harold in Italy, Aspen Concert Orchestra, with Lynne Ramsey Irvine (viola), and Paul Vermel (conductor), recorded by The Aspen Music Festival, Aspen: CO, July 23, 1986, 2 audio discs: digital, CD audio; 4 3/4 in., https://pitkin.marmot.org/Record/.b42456393.
} 
Ramsey's solo career found significant traction during the 1980s. In 1985, she performed the William Walton Viola Concerto at the newly inaugurated Beijing Concert Hall ${ }^{26}$ with the Beijing Center Philharmonic Orchestra as the first non-Chinese musician to perform a solo concerto in this hall. ${ }^{27}$ (See Figure 3.)

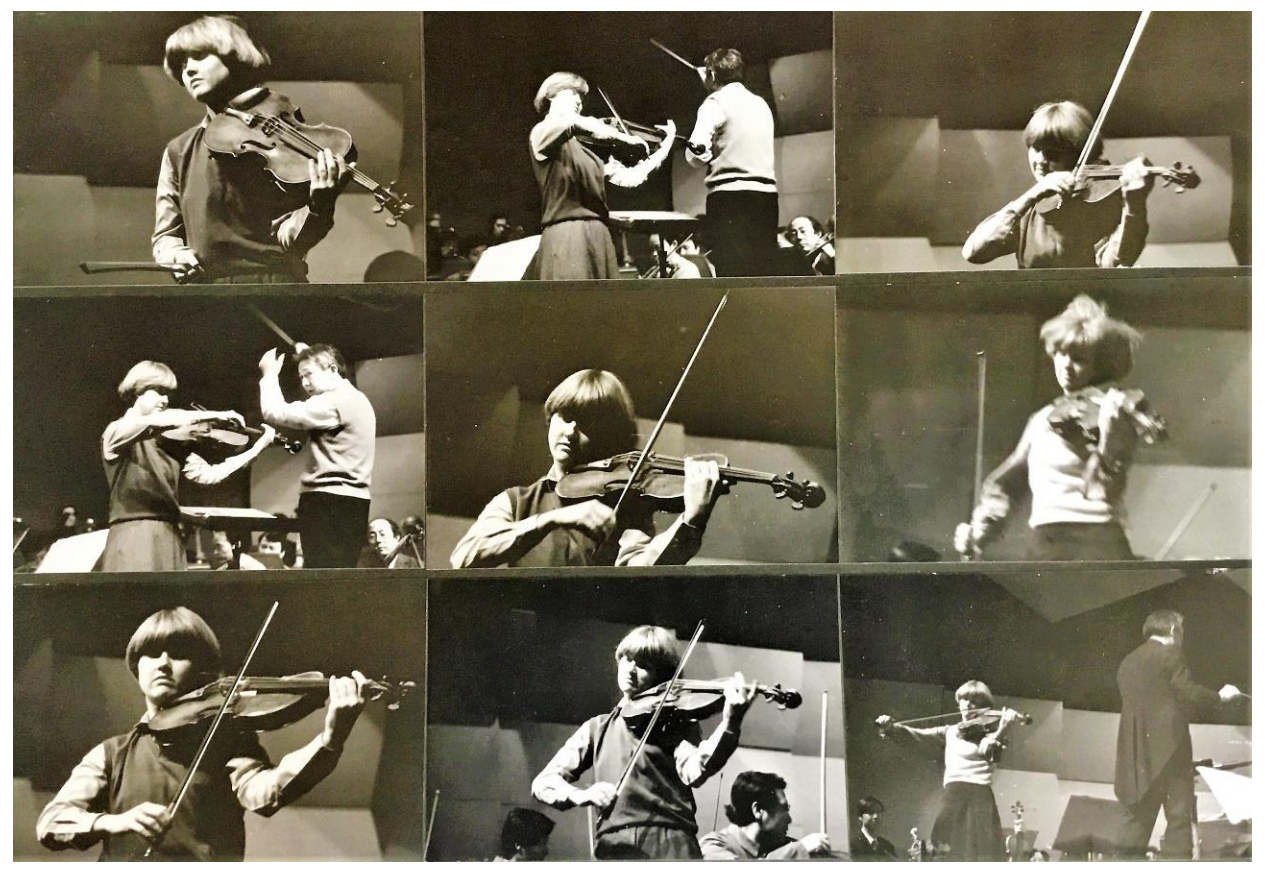

Figure 3. Ramsey Performing with Beijing Center Philharmonic Orchestra in 1985

In 1985, during her tenure as a Pittsburgh Symphony member, Ramsey successfully auditioned for the principal viola position with Detroit Symphony Orchestra, which offered her a three-week long trial. ${ }^{28}$ Even though Ramsey was not hired as a full member of this orchestra, this opportunity motivated her to continue auditioning for principal orchestral positions. Later that year, Ramsey took up a position on the faculty at the Oberlin Conservatory of Music with

26 "Beijing Concert Hall," World Concert Hall, accessed August 14, 2018, https://www.worldconcerthall.com/en/halls/beijing_concert_hall/88/.

27 "Interlochen Viola Institute: Lynne Ramsey," Interlochen Center of the Arts, accessed August 16, 2018, http://camp.interlochen.org/person/lynne-ramsey. Photograph by the author.

${ }^{28}$ Ramsey interview. 
her husband, Jeffrey Irvine. (See Figure 4.) ${ }^{29}$ In 1986 she served briefly as principal violist with the Rochester Philharmonic Orchestra, resigning after just two months to join the Saint Paul Chamber Orchestra as a principal violist. ${ }^{30}$

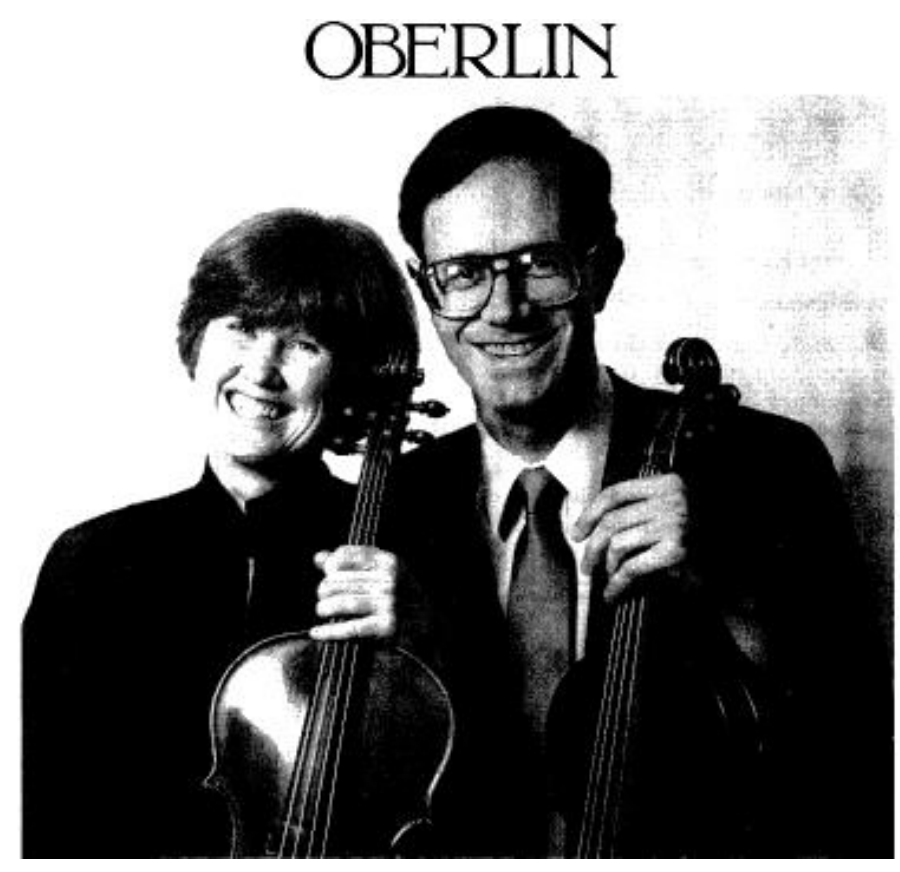

Figure 4. Oberlin Conservatory of Music, Viola Faculty in 1986; Lynne Ramsey Irvine, Viola and Orchestra Studies, Jeffrey Irvine, Viola and Chamber Music

Ramsey's time with the Saint Paul Chamber Orchestra gave her unique performance opportunities. She collaborated with the Orchestra's principal bassist, Chris Brown, in the Sinfonia Concertante for Viola and Bass by Carl Ditters von Dittersdorf (1739 - 1799). Brown and Ramsey had both grown up in Navy families, and they decided to compose their own cadenza for the concerto based on the Navy's official march, "Anchors Aweigh.” Ramsey also performed chamber music with Pinchas Zukerman at Carnegie Hall in $1988 .{ }^{31}$ After a year serving as principal viola with the Saint Paul Chamber Orchestra, Ramsey successfully

29 “Oberlin Conservatory of Music: Viola Faculty," Journal of the American Viola Society, vol. 2, no. 3, (November 1986): 4, http://www.americanviolasociety.org/PDFs/Journal/JAVS-2_3.pdf. Photograph courtesy of the Oberlin Conservatory of Music.

${ }^{30}$ Ramsey interview.

${ }^{31}$ Ramsey interview. 
auditioned for the first assistant principal position with the Cleveland Orchestra. Ramsey joined the orchestra during a period of rejuvenation of the ensemble during Christoph von Dohnány's tenure as artistic director of the orchestra. Replacing Vitold Kushleika (1916-1993), who retired after serving the orchestra for forty seasons, Ramsey joined the orchestra in January of 1989. Her first performances with the orchestra were in a recording session of the Busoni Piano Concerto. ${ }^{32}$ Shortly after the recording session, Ramsey filled in as principal violist and soloist for her first concert with the orchestra, playing the solo from the overture of the Opera, "Irmelin" by Frederick Delius $\left(1862\right.$ - 1934) on short notice. (See Figure 5). ${ }^{33}$

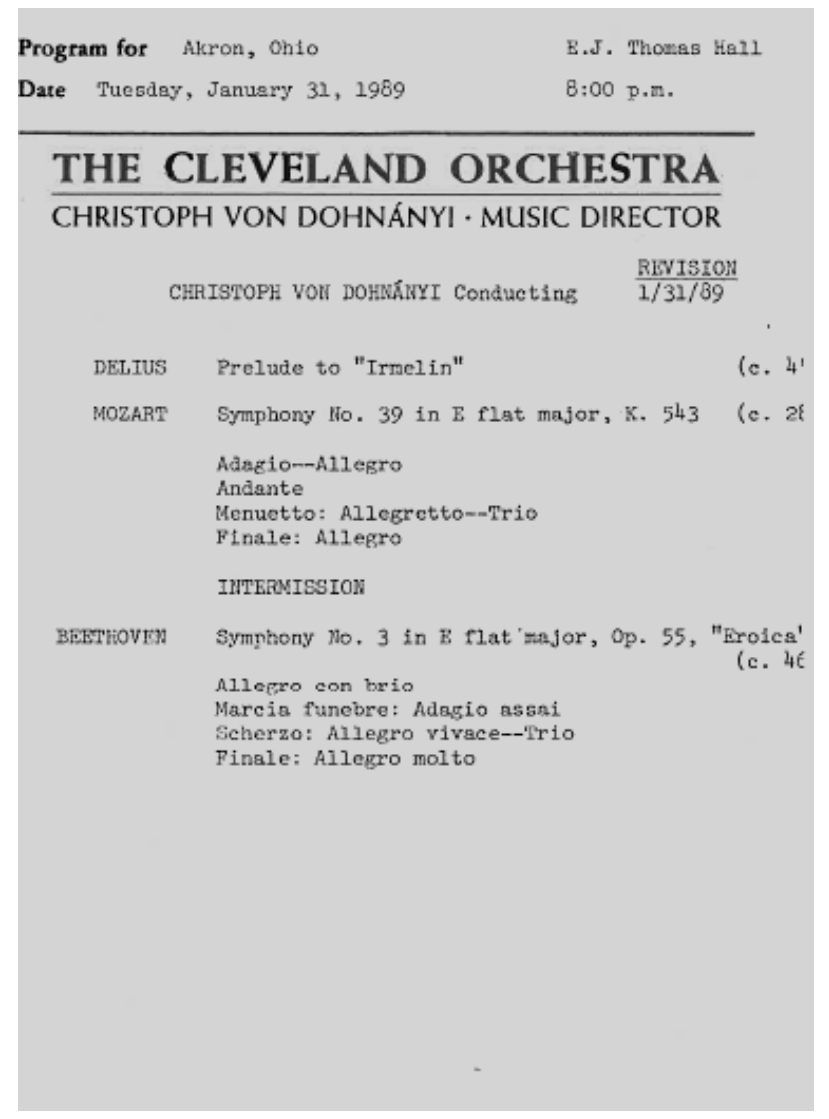

Figure 5. First Concert with The Cleveland Orchestra

\footnotetext{
${ }^{32}$ Donald Rosenberg, The Cleveland Orchestra Story: Second to None (Cleveland: Gray \& Co., 2000), 511-515, https://libwvu-on-worldcat-org.www.libproxy.wvu.edu/oclc/44414148.

33 "From the Archives: About the Archives," The Cleveland Orchestra, accessed August 16, 2018, https://www.clevelandorchestra.com/from-the-archives/orchestra-archives/. Hall Sheet courtesy of The Cleveland Orchestra Archives.
} 
To help understanding the relevance of the Cleveland Orchestra among other symphonies in the world in 2008, Gramophone Magazine prepared a list that ranked the best orchestras in the world, "judging concert performances as well as recording output, contributions to local and national communities and the ability to maintain iconic status in an increasingly competitive contemporary climate." ${ }^{34}$ The Cleveland Orchestra ranked seventh, second among American orchestras to the Chicago Symphony Orchestra. ${ }^{35}$ As of 2018, Ramsey has spent 29 seasons with the Cleveland Orchestra and her tenure there has offered her the opportunity to collaborate in numerous concerts and recordings. In addition to performing as first assistant principal viola in the Orchestra's many at-home concerts and on tours, Ramsey has also played solo and duo concertos with the orchestra, including Bach's Sixth Brandenburg Concerto, which she has played both with Stanley Konopka, who serves as the second assistant principal violist, and with Robert Vernon, who as principal violist was Ramsey's stand partner for 26 seasons. As part of Vernon's final solo appearance with the orchestra, Ramsey premiered Richard Sortomme's Concerto for Two Violas and Orchestra with him. ${ }^{36}$ (See Figure 6.)

\footnotetext{
${ }^{34}$ Rob Cowan, James Inverne, James Jolly, Alex Ross, Mark Swed, Wilhelm Sinkovicz, Renaud Machart, Manuel Brug, Thiemo Wind, Zhou Yingjuan, and Soyeon Nam, "The World Leading Critics Rank: The 20 World's 20 Greatest Orchestras," The Gramophone Magazine, accessed November 24, 2018, https://www.gramophone.co.uk/editorial/the-world\%E2\%80\%99s-greatest-orchestras.

${ }^{36}$ Zachary Lewis, "Cleveland Orchestra Shines Across the Board in Premiere, Schubert's 'Great' Symphony (Review)," Cleveland Plain Dealer, November 20, 2015, https://www.cleveland.com/musicdance/index.ssf/2015/11/cleveland_orchestra_shines_acr.html. Photograph courtesy of Roger Mastroianni.
} 


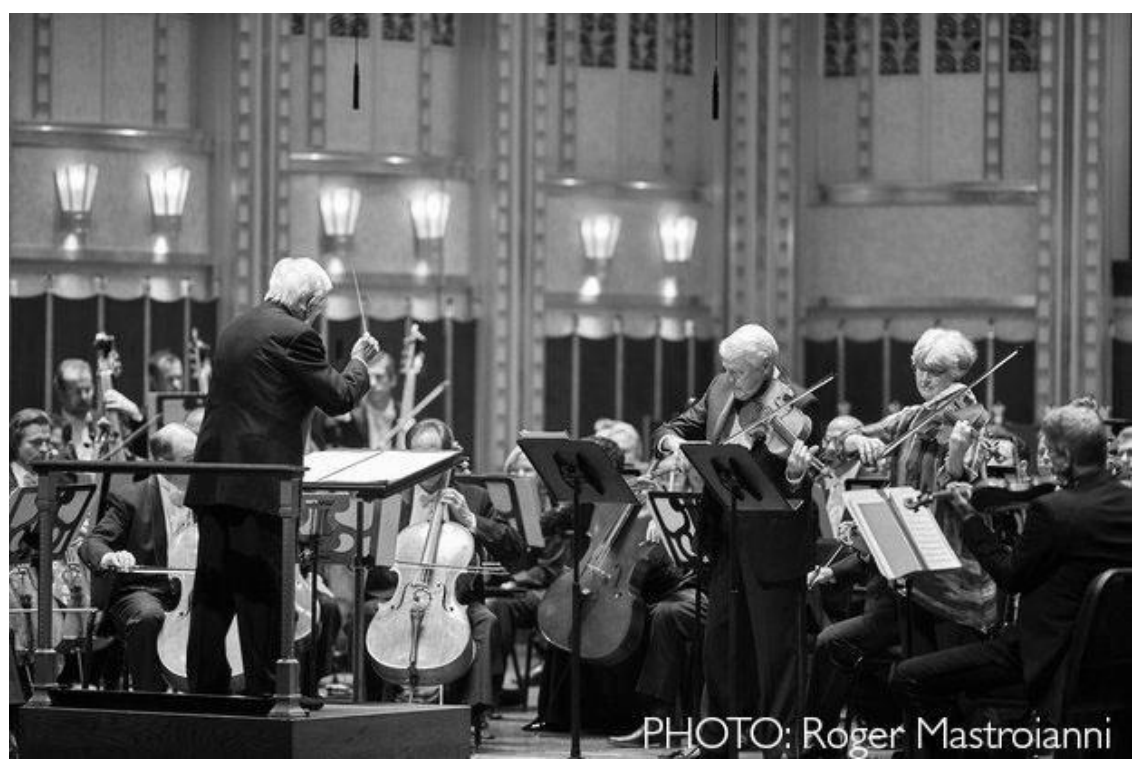

Figure 6. Robert Vernon and Lynne Ramsey Performing the Sortomme Concerto for Two Violas and Orchestra with The Cleveland Orchestra and Christoph von Dohnányi, (Conductor)

In addition to playing with orchestras, Ramsey's musical career has also always included chamber music. Ramsey joined the string quartet Amici, comprised of members of the Cleveland Orchestra, in 1989, and they perform on a regular basis. ${ }^{37}$ Ramsey has performed with harpist Ursula Holliger and with violinist Paul Kantor, and with the Cleveland-based Panorámicos ensemble, which advocates for new music and $20^{\text {th }}$ century music repertoire. This ensemble received rave reviews from Gramophone Magazine with their debut album in 2004:

"Panorámicos: chamber music for winds, strings, and piano": "Eclectic in the best sense of the word...," “...a top North American pick." ${ }^{38}$ In 2009, the ensemble recorded the album, Joie de vivre!, which included collaborations with artists such as the horn player Richard King and

\footnotetext{
37 “Arts Renaissance Tremont: Amici String Quartet Performance,” ClevelandClassical.com, accessed August 19, 2018, https://clevelandclassical.com/arts-renaissance-tremont-amici-string-quartet-february-15/. This website describes a performance of the Amici String Quartet. As part of the performance, music critic and writer Donald Rosenberg offered a pre-concert lecture.

${ }^{38}$ Joie de Vivre!, with Panorámicos Ensemble, recording engineer, Everett Porter, December 1, 2009, https://www.amazon.com/Joie-Vivre-Panor\%C3\%A1micos/dp/B0030V0OWA.

The Gramophone review of the recording, Panorámicos: Chamber Music for Winds, Strings, and Piano is found on the cover of Joie de Vivre!
} 
violist Jeffrey Irvine. ${ }^{39}$ In 2009, Panorámicos recorded their third album, Reflections with

Sandra Simon, ${ }^{40}$ which included Hindemith's Trauermusik, showcasing Ramsey and pianist

Randall Fusco. Music critic Donald Rosenberg, who covered the Cleveland Orchestra concerts

for the Cleveland Plain Dealer for twenty-eight years, described Ramsey and Fusco as

“...eloquent protagonists in Hindemith’s Trauermusik. Grade: A.” 41

Besides the successful recording projects with Panorámicos ensemble, Ramsey also joined chamber groups formed by the flutist Michael Debost ${ }^{42}$ and the violinist and member of the Amici String Quartet Takako Masame to record the 2009 album Serénádes, which including pieces composed by Reger and Beethoven. ${ }^{43}$ In 2012, Ramsey joined a group of musicians from the Cleveland Orchestra and faculty members from the Cleveland Institute of Music to record Chamber Music for Horn, featuring Richard King. ${ }^{44}$

Teaching has always been an important aspect of Ramsey's career. Ramsey joined the faculty at the Oberlin Conservatory of Music in 1985 and remained there until $1997 .{ }^{45}$ While still teaching at Oberlin, she joined the viola faculty of the Cleveland Institute of Music in 1989. Combining the two teaching jobs and her position at the Cleveland Orchestra worked well for

${ }^{39}$ Joie de Vivre!, with Panorámicos Ensemble, recorded in Cleveland, OH: Panorámicos, 2009, 1 audio disc: digital CD audio; 4 3/4 in., https://libwvu-on-worldcat-org.www.libproxy.wvu.edu/oclc/502142051.

${ }^{40}$ Reflections with Sandra Simon, with Panorámicos Ensemble, recorded in Cleveland, OH: Panorámicos, 2009, 1 audio disc: digital CD audio; 4 3/4 in., https://libwvu-on-worldcat-org.www.libproxy.wvu.edu/oclc/502264265.

${ }^{41}$ Donald Rosenberg, review of "Reflections," by Panorámicos Ensemble, Cleveland Plain Dealer, December 13, 2009, http://www.cleveland.com/musicdance/index.ssf/2009/12/classical_cds.html.

${ }^{42}$ Robert Cummings, "Michael Debost: Biography," AllMusic, accessed August 20, 2018, https://www.allmusic.com/artist/michel-debost-mn0000070348/biography.

Cumming's resume includes teaching appointments as part of the faculty of the Conservatoire de Paris, and performance appointments such as the appointment as first flutist of the Orchestre de Paris.

${ }^{43}$ Sérénades, with Michael Debost (flute), Lynne Ramsey (viola), and Takako Masame (violin), recorded at the Baldwin-Wallace College Conservatory of Music, Berea, OH: Skarbo, performed February 10, 2008, 1 audio disc: digital, stereo; 4 3/4 in., https://libwvu-on-worldcat-org.www.libproxy.wvu.edu/oclc/213329022.

${ }^{44}$ Chamber Music for Horn, with Richard King, (horn), Jesse McCormick, (horn), Jung Eun Oh, (soprano), JungMin Amy Lee, (violin), Mari Sato, (violin), Lynne Ramsey, (viola), Stanley Konopka, (viola), Julie Myers King, (cello), Paul Kushious, (cello), Orli Shaham, (piano), recorded in Oberlin OH: Albany Records, 2012, recorded May - June 2011, 1 audio disc: digital, 4 3/4 in., https://libwvu-on-worldcat-org.www.libproxy.wvu.edu/oclc/882436086.

45 "Orchestra Members: Lynne Ramsey," The Cleveland Orchestra, accessed August 16, 2018, http://www.clevelandorchestra.com/About/Musicians-and-Conductors/Meet-the-Musicians/M-S-

Musicians/Ramsey-Lynne/. 
Ramsey for four years, but after her first child was born, she took a leave of absence from the

Cleveland Institute of Music until $2001 .^{46}$ Ramsey also holds a faculty position at the Interlochen

Center of the Arts and has taught at the Encore Music Festival, founded by David Cerone. ${ }^{47}$

Ramsey's remarkable trajectory as a viola pedagogue was recognized in 2014 by the American

Viola Society with the Maurice W. Riley Award for "Distinguished Contributions to the Viola in

Teaching, Scholarship, Composition, Philanthropy, or Service to the AVS." 48

Ramsey's distinguished career as a violist and mentor is well known within the closest

circles of musicians that have performed with and learnt from her. Nevertheless, her

contributions to the viola world are worth sharing with a wider public that might be eager to

learn how far this musician has gone by having the right attitude and tools. In the next chapter, I

offer a description of her routines as a violist, including topics such as preparation for orchestral auditions, professionalism in large ensembles, and warm-up exercises for violists.

\footnotetext{
46 “String Faculty: Lynne Ramsey,” Cleveland Institute of Music, last modified August 20, 2013, http://archive.li/Optpg.

This website shows an outdated version of the faculty from the Cleveland Institute of Music. However, this website contains a Ramsey's resume with the year in which she was reappointed as faculty member of the Cleveland Institute of Music.

47 "2011 Lifetime Achievement Award for Music and Dance: David Cerone," Cleveland Arts Prize, accessed August 18, 2018, http://clevelandartsprize.org/awardees/david_cerone.html.

This website shows some of the highlights of Cerone's teaching career such as appointments as part of the faculty of the Curtis Institute of Music and the Cleveland Institute of Music.

48 “2014 American Viola Society Awards Announcement,” American Viola Society, accessed August 18, 2018, http://studio.americanviolasociety.org/blog/2014/06/american-viola-society-awards-announcement/.

This website shows that Ramsey was awarded "in recognition of distinguished performance as First Assistant Principal Viola of The Cleveland Orchestra since 1989 and for her distinguished teaching at the Cleveland Institute of Music and the Aspen Music Festival".
} 


\section{CHAPTER 2}

\section{RAMSEY AS A PERFORMER}

This chapter focuses on Ramsey's career as a performer. The topics in this chapter include Ramsey's warm-up and practice routines, strategies for auditioning, and how to maintain an orchestral job. While there have been other documents written on similar topics, this is the first to focus on Ramsey's practices. These documents include John Jake Kella's dissertation, “The Development and Qualitative Evaluation of a Comprehensive Music Curriculum for Viola, with an Historical Survey of Violin and Viola Instructional Literature from the $16^{\text {th }}$ Through $20^{\text {th }}$ Centuries, Including a Review of the Teaching Concepts of William Lincer" and Minor Lewis Wetzel's dissertation, “A Better Bartók—Dilemmas and Solutions in Performing Bartók's Viola Concerto." In his dissertation, Kella shares warm-up routines, practice techniques, and exercises recommended by violist William Lincer. ${ }^{49}$ Minor Lewis Wetzel describes the practice routines of violist Paul Hindemith. ${ }^{50}$ In a research paper by the bassist Christopher Rose, Rose covers topics related to the audition process and professionalism for bass players in orchestras which aligns with a section of this chapter related to Ramsey's recommendations to orchestral violists. ${ }^{51}$ Additionally, Emily Jensenius's thesis analyzes $20^{\text {th }}$ century viola etudes, such as the sets prepared by Garth Knox and Michael Kimber, as well as guidance for students in learning the required performance skills through these etudes, prior to play other challenging viola pieces composed during the $20^{\text {th }}$ and $21^{\text {st }}$ century. Matthew Dane's thesis aims to portray Tuttle's influence in the contemporary viola pedagogy, and his document includes fragments of

\footnotetext{
${ }^{49}$ Kella, "The Development and Qualitative Evaluation of a Comprehensive Music Curriculum for Viola, with an Historical Survey of Violin and Viola Instructional Literature from the $16^{\text {th }}$ Through $20^{\text {th }}$ Centuries, Including a Review of the Teaching Concepts of William Lincer." 560-567.

${ }^{50}$ Weltzel, “A Better Bartók-Dilemmas and Solutions in Performing Bartók's Viola Concerto,” 25, 26.

${ }^{51}$ Rose, "An Orchestra Audition Preparation Handbook for Bass Players." 20-35.
} 
interviews with former students of Tuttle describing their experience with Tuttle and their vision on the "Coordination" technique. ${ }^{52}$

Chien-Ju Liao's work also seeks to help violists auditioning for an orchestral position with a unique method in which players perform all-viola arrangements of standard symphonic repertoire. Several of the articles that published by the Journal of the American Viola Society are also noteworthy in terms of contextualizing the viola repertory. Myron Rosenblum's 2002 article on the rediscovery of an unpublished viola concerto composed by Ignatz Gspan; ${ }^{53}$ Melissa Claisse's 2017 interview made with violist Jutta Puchhammer-Sédillot, who rediscovered and recorded a set of French show pieces composed during the turn-of-the $20^{\text {th }}$ century ${ }^{54}$ and Andrea Houde's recent premiere and recordings of Walter Piston's Interlude and Eine Liebes-Novelle by Benjamin Cutter are all important materials. ${ }^{55}$ Finally, for readers seeking a historical background of the viola, I recommend the dissertation prepared by Peter Neubert, which discusses important information about the development of the viola during the $19^{\text {th }}$ century in Paris. ${ }^{56}$ Neubert describes the switch that the viola, as an instrument, experienced during the $19^{\text {th }}$ century when the music community started to demand higher performance skills from violists in

\footnotetext{
${ }^{52}$ Dane, "Coordinated Effort: A Study of Karen Tuttle's Influence on Modern Viola Teaching."

${ }^{53}$ Myron Rosenblum, "From Discovery to Publication: The Path of $18^{\text {th }}$-Century Ignatz Gspan's Concerto for Viola and Strings," Journal of the American Viola Society, vol. 18, no. 2 and 3: 77, http://www.americanviolasociety.org/PDFs/Journal/JAVS-18.23.pdf.

${ }^{54}$ Melissa Claisse, "The Pièces de Concours: Rediscovered Treasures from Turn-of-the-Century France: A Conversation with Violist Jutta Puchhammer-Sédillot," Journal of the American Viola Society, With Viola in Hand, vol. 33, (Summer 2017): 43, https://www.americanviolasociety.org/DownloadFile.php?FN=JAVS-Summer-2017.pdf.

${ }_{55}^{55}$ The American Viola, with Andrea Houde (viola), and Sun Jung Lee (piano), recorded at West Virginia University, Morgantown: WV: Albany Records, November 1, 2018, https://www.amazon.com/dp/B07KBJ2TMW/ref=sr_1_2?ie=UTF8\&qid=1541783549\&sr=82\&keywords=Andrea+Houde+viola\&fbclid=IwAR39Okd2vxSqvnOIVjOusNv1mPM69tTiuWkGA9dwOPbtel YW jGLw_Dle6Y.

The Piston Interlude was previously unrecorded despite being composed by a well-known composer. And, the Cutter's Eine Liebes-Novelle is believed to be the first American viola work and yet was also previously unrecorded and unknown.

${ }^{56}$ Neubert, "The Development of Viola Instruction at the Paris Conservatoire during the Nineteenth Century and the Evolution of an Idiomatic Style of Writing for the Viola as seen through the Music of the Viola Concours, 18961918."
} 
new compositions. This, in turn, offered the viola community the opportunity to flourish. As the number of violists grew larger, a pedagogical approach specific to the viola developed in Paris, which resulted in such as the creation of the first viola class, in $1894 .{ }^{57}$ These doctoral documents and journal articles align with topics that will be discussed in this research document and serve to offer broader information to elucidate the topic at hand. The information in this chapter was collected from an interview with Ramsey; a recorded masterclass; and materials containing comments from Karen Tuttle, Ramon Scavelli, and Ramsey's husband, Jeffrey Irvine.

\section{Warm-Up Routine}

Ramsey has played at a very high level throughout her professional career, and her dedication to individual practice has greatly contributed to this. Ramsey dedicates two hours of daily practice to maintain her playing level, and a total of three to four hours of individual practice if she is learning new repertoire. Furthermore, although Ramsey agrees with the idea of taking a day off from practicing every week, her workload with the Cleveland Orchestra often challenges her ability to do so. ${ }^{58}$ An important component of Ramsey's individual practice is her warm-up routine, and her current routine is the result of over half a century of refinement. Ramsey's systematic and organized formula has been very successful during her career and could be beneficial to other violists and other string players as well. The main components of this 40-minute-long warm-up routine include techniques derived from Tuttle's viola technique, bowing exercises provided by Irvine, and Ramsey's own additions. Ramsey has practiced this routine throughout her career, even after suffering injuries caused by constant playing. This warm-up routine could serve as a guide for violists recovering from playing injuries, after seeking medical advice. Moreover, this routine covers most of the techniques that a violist will

\footnotetext{
${ }^{57}$ Neubert, "The Development of Viola Instruction" 73.

${ }^{58}$ Ramsey interview.
} 
find in orchestral, chamber music, and solo repertoire. These techniques include exercises to develop bowing technique, the independence of the fingers, vibrato, shifting, and double stop accuracy. The sections dedicated to the left-hand technique, such as the vibrato exercise and the three-octave scale with the use of the "Plop and Slur" concept, have been especially effective for me.

Ramsey begins her warm-up routine with an exercise that aims to activate the right-arm motion needed while playing down- and up-bows. Figures 7 and 8 illustrate parts of this first exercise. First, the exercise requires the player to keep the bow placed on the string in the lower half of the bow without moving its placement on the string. Then, still without moving the bow, the player should lift their right elbow several times, simulating short up-bow motions. Next, still without moving the placement of the bow on the string, the player lowers the right elbow several times, simulating short down-bow motions. Once the player has practiced these two motions, the next step is for the player to connect both motions together, still without moving the bow.

An exercise related to tone production continues the warm-up routine. This is based on the concept of Son Filé, which calls for a long and sustained tone without any change in dynamics. ${ }^{59}$ This exercise serves to develop a consistent slow bow motion from the frog to the tip. With the metronome set at 60 beats per minute, the player should draw the bow back and forth from frog to tip while playing an open $\mathrm{C}$ string. Starting at four beats per bow, each new bow adds four more beats until the player is bowing at twenty-four beats per bow-stroke. ${ }^{60}$

\footnotetext{
${ }^{59}$ Owen Jander and Ellen T. Harris, “Son Filé," Grove Music Online, accessed June 11, 2018, https://doi-org.www.libproxy.wvu.edu/10.1093/gmo/9781561592630.article.26206.

${ }^{60}$ Ramsey interview.
} 


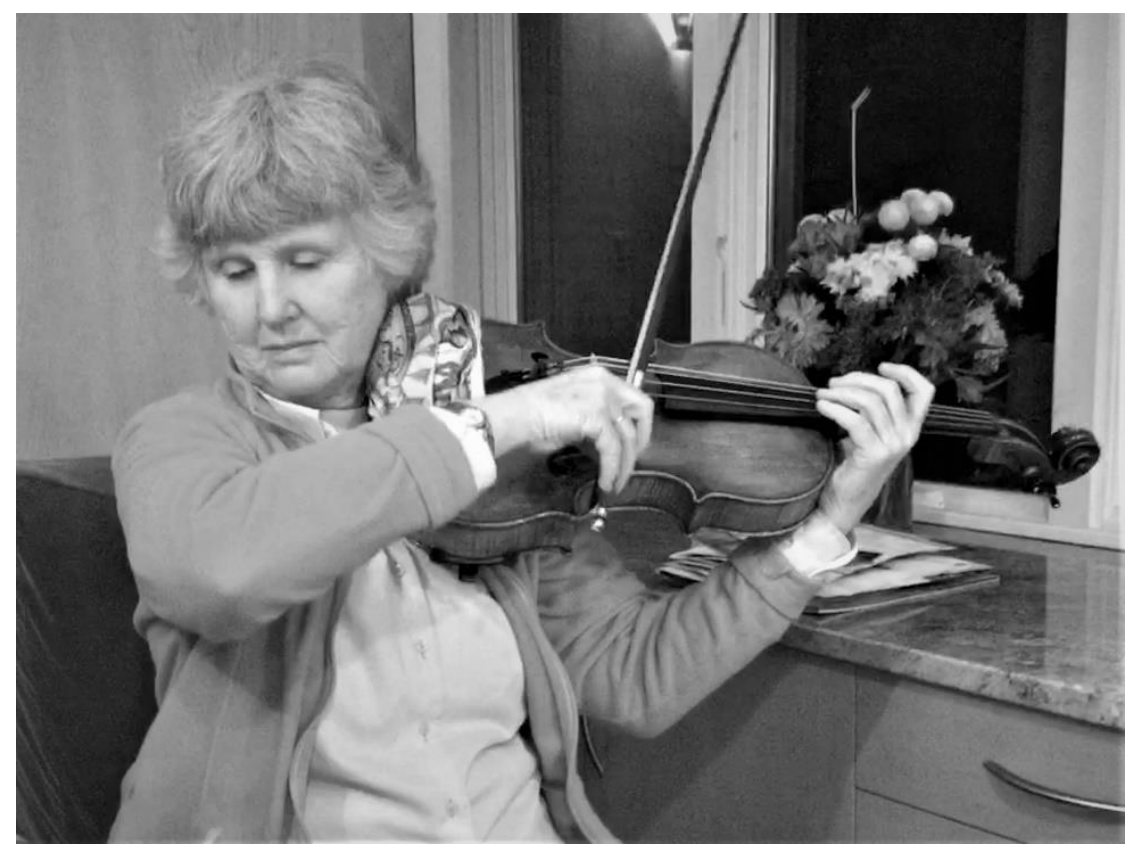

Figure 7. Raised Position of the Elbow during the Up-Bow Motion

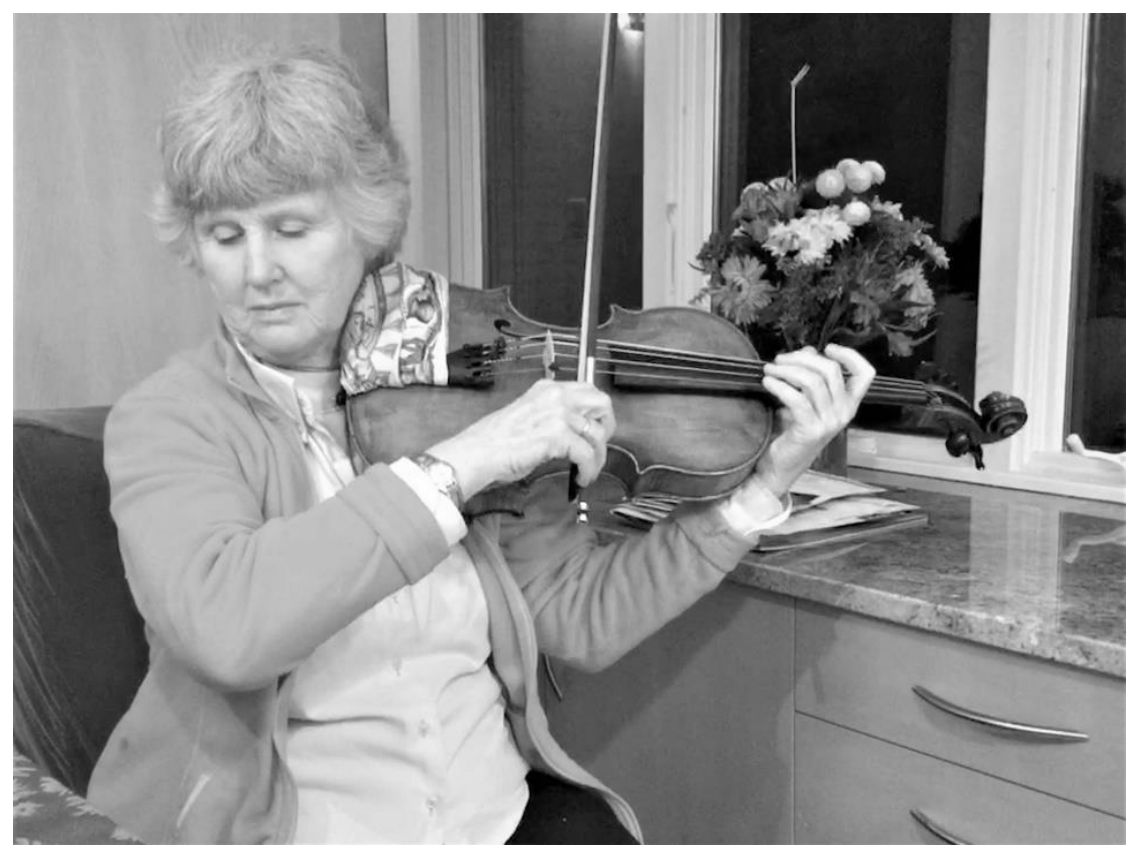

Figure 8. Lowered Position of the Elbow during the Down-Bow Motion 
The warm-up routine continues with exercises for the independence of each finger on the left hand. Ramsey learned this useful technique from Tuttle, who called it, "Plop." "Plop" refers to the dropping and release of each finger of the left hand on the fingerboard. To achieve each finger's independence, every finger starts its movement from the base knuckle. ${ }^{61}$ This exercise is also applied on a slur, which then it is called, "Plop and Slur." ${ }^{62}$ The procedure for "Plop and Slur" serves to slur any given pair of notes. The player is to play the same note twice, once on a down- and once on an up-bow, and then add the second note to the up-bow. The repeated note is "plopped" on the up-bow, which helps connecting to the second note during the slur. (See Figure 9.)
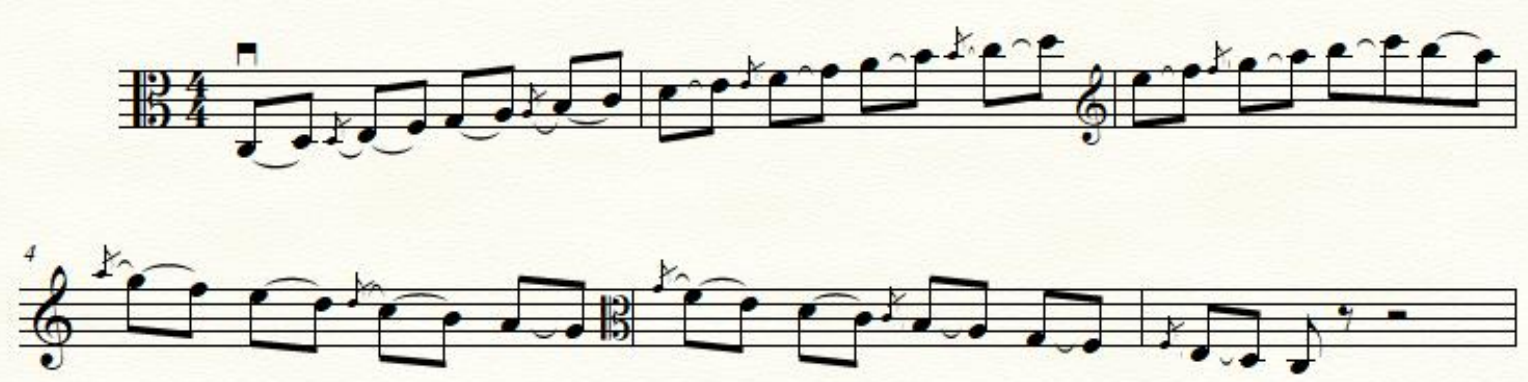

Figure 9. C Major Three-Octave Scale Divided into Two Notes Per Bow Using the "Plop and

\section{Slur" Technique}

Ramsey applies the "Plop and Slur" method to three- or four-octave scales using a legato bow-stroke at 60 beats per minute, slurring two notes per bow. Figure 9 provides an example of this exercise in a $\mathrm{C}$ Major three-octave scale. The grace note added in this musical example indicates the repeated note which is "Plopped and Slurred." This repeated note is added on the scale by following the next system: while ascending on the scale, Ramsey repeats the last note of each down-bow on the next up-bow. Then, while descending, the last note played on each up-

\footnotetext{
${ }^{61}$ Burns, "Coordinated Action," 68.

${ }^{62}$ Ramsey interview.
} 
bow is repeated on the next down-bow. After playing the scale with this slurring pattern, Ramsey continues playing the scale with three, four, five, six, eight, and twenty-four notes per bow. Next, the scale is practiced with the use of détaché bow-stroke. ${ }^{63}$ Ramsey plays each note of the scale twice. When ascending, she uses only the frog end of the bow; when descending, she uses only the tip of the bow. ${ }^{64}$ The right upper arm needs to be active for a clean détaché bow-stroke at both the frog and tip. The same scale is then practiced using only the middle of the bow while repeating each note four times. In the middle of the bow, the upper right arm also needs to be flexible and the player must allow the right-elbow joint to open and close freely while playing. ${ }^{65}$

Continuing the warm up, Ramsey then practices an exercise that consists of playing a series of fast and light whole bows on any open string. This simple exercise serves to increase flexibility in how quickly the right hand adapts to using each part of the bow. Then, she practices the martelé bow-stroke in a three- or four-octave scale. To do so, Ramsey follows the ascending and descending contour of the scale while repeating each note twice on a different bow-stroke. She uses the lower half of the bow while ascending the scale, and then uses the upper half of the bow while descending the scale. Finally, she plays the scale again while still repeating each note of the scale twice and using the entire bow for each note. (See Table 1.)

The warm-up continues with spiccato bow-strokes. While playing a series of short strokes starting in the middle of the bow, the player slowly moves the bow towards the lower half of the bow until they find the bounciest part of the bow. The bow is placed on the string just

${ }^{63}$ Lynne Ramsey, private message to author, November 15, 2018.

As Ramsey described to the author: "all bow-strokes come from a good détaché which is only back and forth initiating with the forearm opening and closing the elbow joint and allowing the hand to react." In other words, Ramsey thinks that the détaché bow-stroke integrates the opening and closing motion of the elbow which is initiated from the forearm, and from this motion, the right hand reacts by adapting its shape on each part of the bow. She continues by saying that "another way to look at it would be how the notes begin from softest attack to hardest: legato, détaché, staccato, martelé."

${ }^{64}$ The tempo for this scale could be $60 \mathrm{bpm}$, and the bow-speed for this needs to be slow enough to keep the bow at the frog while ascending, and at the tip while descending.

${ }^{65}$ Ramsey interview. 
below the middle of the bow. (See Figure 10.) Once the player has placed the bounciest part of the bow on the string, they play a three- octave scale while repeating each note four times, then two times, and finally playing the whole scale without any note repetitions ${ }^{66}$ She starts this exercise by repeating each note several times in order to focus on the bow-stroke at the beginning and to be able to play the bow-stroke accurately without repetitions at the end of the exercise.

Table 1. Exercise to Practice the Martelé Bow-Stroke on a Three-Octave Scale

Part 1 of the Martelé
Bow-Stroke Exercise.
Play an ascending three-
octave scale using a
martelé bow-stroke.
Repeat each note twice
on a different bow-stroke
in the lower half of the
bow

${ }^{66}$ Ramsey interview. 
Part 3 of the Martelé Bow-Stroke Exercise. Play an ascending and descending three-octave scale using a martelé bowstroke. Repeat each note twice on a different bowstroke and use the whole bow for each note

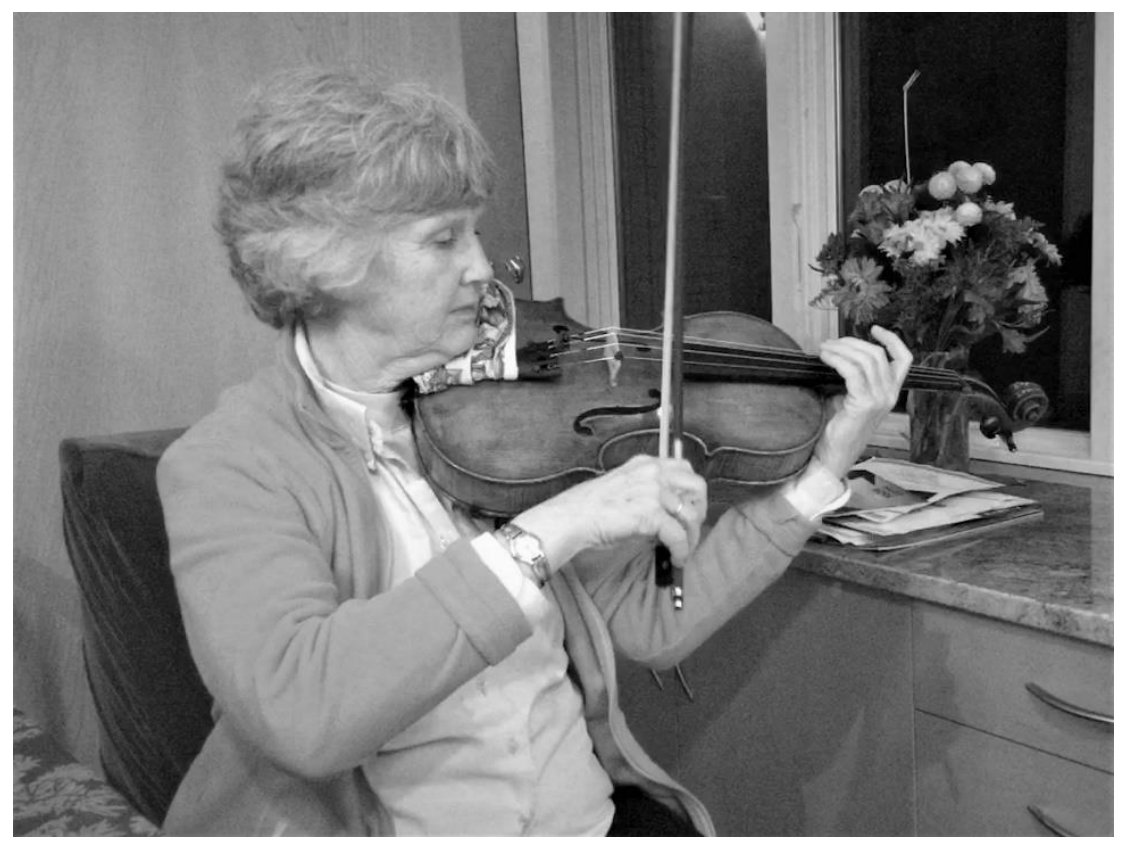

Figure 10. Placement of the Bow for Spiccato Bow-Stroke

The warm up routine also includes several three octave arpeggio sequences: i, I, vi6, IV6, iv6, \#ii 4/2 and I7. This sequence was originally developed by Carl Flesch ${ }^{67}$, and while Flesch's system presents a variety of bow-strokes, Ramsey prefers to practice it with a détaché bowstroke and the "Plop and Slur" technique. She slurs three notes per bow and repeats the last note of each bow on the next bow-stroke. The exercise is then practiced with four and five notes per

${ }^{67}$ Carl Flesch, Scale System (New York, NY: Carl Fischer, Inc., 1942), https://libwvu-on-worldcatorg.www.libproxy.wvu.edu/oclc/7630549. 
bow. After finishing all the previous combinations with the détaché bow-stroke, she plays the arpeggios again, dividing them into three notes per bow and with a staccato bow-stroke. ${ }^{68}$ Double stops follow in Ramsey's warm up routine. She first practices broken double stops, which allow her to practice intonation accuracy and revisit the "Plop" concept. To play a broken double stop, players play each note of the double stop separately. The two pitches of the double stop can be played on the same bow or with different bow-strokes. Then, on a new bow-stroke, both pitches are played simultaneously while maintaining a relaxed left hand. Ramsey practices a one-octave scale of broken thirds on only two strings and then broken octaves using all the four strings. She uses Ševčík's étude book, Shifting: Changes of Position, op. $8,{ }^{69}$ as a reference for double stop exercises. To conclude her warm up, Ramsey practices an exercise originally written by Jean-Louis Duport $(1749-1819)^{70}$ and transposed for the viola by Irvine, shown in Figure 11. This short excerpt is practiced using various rhythms and bow-strokes, all of which help develop a strong foundation for rapid string crossings. ${ }^{71}$

\footnotetext{
${ }^{68}$ Lynne Ramsey, private message to author, November 15, 2018. For Ramsey, "staccato [bow-stroke] has space between down [- and] up [-bow] and the beginning of the note is not accentuated as is the martelé [bow-stroke.]"

${ }^{69}$ Otakar Ševčík, Shifting, Changing the Position, op. 8, trans. and ed. Max Aronoff (Bryn Mawr, PA: Elkan-Vogel, 1946).

${ }^{70}$ Jean-Louis Duport, Essai sur le Doigté du Violoncelle et sur la Conduite de L'Archet (Paris, France: Janet, 1824), exercise no. 7: 202, https://play.google.com/books/reader?id=pApDAAAAcAAJ\&pg=GBS.PP202.

${ }^{71}$ Ramsey interview.
} 


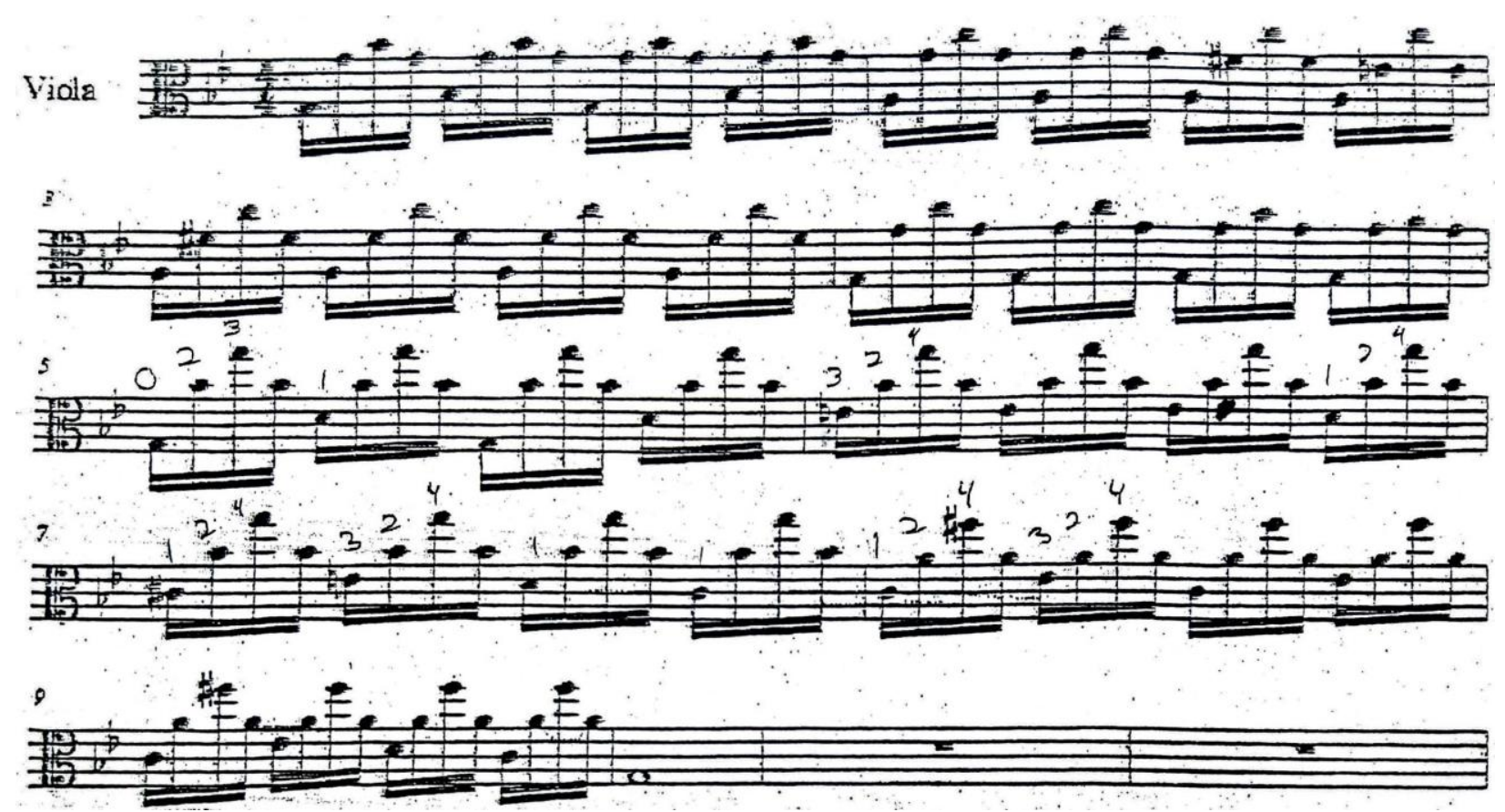

Figure 11. Bowing Exercise Transcribed and Edited by Irvine

\section{Practice Exercises after the Warm-Up}

After Ramsey finishes her warm up routine, she begins the second part of her individual practice session, which covers current solo, orchestral, and chamber music repertoire. Her preparation for these types of repertoire does not differ greatly, but the time she dedicates to each of them does. The orchestral repertoire demands most of Ramsey's practice time, followed by repertoire for the Amici String Quartet. Her time commitments are dedicated to the Cleveland Orchestra and to her string quartet because of the workload of each of these groups. For instance, between 1989 and 2000, the Cleveland Orchestra premiered forty-five compositions and recorded more than a hundred and thirty pieces. ${ }^{72}$ Ramsey's demanding schedule requires her to learn large amounts of repertoire very quickly, and in addition to devoting most of her practice

\footnotetext{
${ }^{72}$ Donald Rosenberg, The Cleveland Orchestra Story: Second to None (Cleveland: Gray \& Co., 2000), 651-680 https://libwvu-on-worldcat-org.www.libproxy.wvu.edu/oclc/44414148.
} 
time to this music, she also spends considerable time listening to recordings of the programmed pieces so that she can spot the most challenging passages and understand how the viola part fits with the rest of the orchestra or quartet. At this point in her career, listening to recordings has proven to be very effective for Ramsey since the warm up part of her practice time requires more time than in the past. This is due to Ramsey needing a longer time period for her muscles to fully warm up at this point in her life. ${ }^{73}$

\section{Practicing with the Metronome}

One technique that Ramsey often uses while practicing is to start at a slow tempo and then slowly speed up the metronome. By doing so, Ramsey can polish a challenging passage and perform it well in a consistent manner. For example, a virtuosic viola passage such as the first page of Richard Strauss's symphonic poem, Don Juan, requires a slow starting tempo. ${ }^{74}$ Once the passage is mastered at a slow tempo, it can be slowly sped up to the stated tempo. When Ramsey first learned this passage, her starting tempo was twice as slow as performance tempo. During the first practice session of a challenging passage like the opening of Don Juan, Ramsey recommends beginning by playing the passage at one-half its normal speed and then moving up in tempo two beats per minute at a time. This system increases the tempo very slowly while allowing the violist to reach the performance tempo in just a few practice sessions. Each day the violist should begin their practice of the passage at a faster tempo than the day before. Once the performer is able to play the passage at the performance tempo, Ramsey then recommends repeating the process at a faster pace. In other words, the violist should still start practicing the passage at half the speed of the performance tempo, but each time the passage is practiced, the tempo should be increased by more than the initial two beats per minute for each play-through.

\footnotetext{
${ }^{73}$ Ramsey interview.

${ }^{74}$ Richard Strauss, Don Juan, op. 20, Viola Part, (New York, NY: Edwin F. Kalmus, 1993): 42-47, https://libwvu-on-worldcat-org.www.libproxy.wvu.edu/oclc/613307550.
} 
Finally, she recommends that the passage should be practiced above the ideal tempo in order to find the performance speed less challenging. ${ }^{75}$ This slow practice has proven to be beneficial for Ramsey, especially while preparing for orchestral auditions.

While practicing the passage at a slower tempo, players can also distribute the bow more efficiently than at a faster speed; practicing at a slow tempo enables the player to practice shifting between positions so as to make their shifts smooth and accurate. An additional technique Ramsey recommends in a slow tempo helps with string crossings and change of positions and is what Tuttle called, "Cross, Shift, Plop." It increases the violist's awareness of both hands while shifting or crossing strings. Players must practice it saying the word "Shift" out loud while changing positions and "Cross" while crossing strings. Finally, the note on the new string or position is plopped, which, as I've described above, refers to the dropping and release of the fingers of the left-hand.

\section{An Example on How to Improve Intonation in an Orchestral Excerpt}

When a specific passage is challenging to play in tune, Ramsey uses both a tuner and a recording device during her practice sessions. Generally, she centers every fingered note of a passage in tempered intonation, which she checks with the aid of the tuner. Then she records herself playing and compares the recording with the tuner. She makes a note of every individual pitch that differs from the tempered intonation shown on the tuner. This serves as a reminder for future practice sessions. For instance, violists auditioning in the United States are frequently asked to perform the first two pages of the second movement of Beethoven's Symphony No. $5 .^{76}$

\footnotetext{
${ }^{75}$ Ramsey interview.

${ }^{76}$ Ludwig van Beethoven, Symphony no. 5 in C Minor, op. 67, Viola Part, ed. by Jonathan Del Mar, (Kassel, Germany: Bärenreiter Verlag, 1999), https://www.baerenreiter.com/en/shop/product/details/BA9005_79/.
} 
This excerpt contains challenging intonation passages. ${ }^{77}$ The first A-flat in the first measure is usually played with the first finger, which requires an extension in the left hand. Since this motion requires a brief re-balancing of the left-hand, intonation issues are common. In the same measure, the B-flat, which acts as a passing tone between the $\mathrm{C}$ and $\mathrm{A}$-flat, can also suffer intonation issues. These two pitches might cause the B-flat to be out of tune due to their strong harmonic pull. Ramsey's practice of this piece emphasizes left-hand finger independence, which keeps the spacing between the fingers even, and uses the recorder and tuner to make sure she is performing this passage in tune.

\section{How to Organize Phrasing Ideas}

As an orchestral player, it is essential to play with rhythmic accuracy. While reviewing rhythm in excerpts such as the beginning of the second movement of Beethoven's Symphony No. 5, Ramsey's practice technique is to play the melody in smaller subdivisions. She suggests that players play this excerpt in separated $32^{\text {nd }}$ notes. By playing the subdivisions of the melody, players can find the natural phrase easily. In order to understand the organization of musical ideas in lyric melodies such as the one found in the same excerpt, Ramsey recommends that players think of the first seven measures together as a group, which helps players to continue the melodic line and avoids unwanted breaks during notes with long rhythmic values. Specifically, the phrase should begin with first measure and end on the E-flat in the measure 7. Another example is the Scherzo from Mendelssohn's A Midsummer Night's Dream. The main melody of the Scherzo is first stated by the flutes and is then passed to the violins while the violas play the rhythmic accompaniment. One of the main difficulties of this excerpt is phrasing the rhythmic accompaniment in parallel with the melody, in part because of the spiccato and sautille bow-

\footnotetext{
${ }^{77}$ Christine Rutledge, "Orchestral Training Forum: Orchestra Repertoire Lists," Journal of the American Viola Society, vol. 17, no. 1 (spring 2001): 61-65, https://www.americanviolasociety.org/PDFs/Journal/JAVS17.1.pdf\#page $=62$.
} 
strokes of the viola part. To improve the bow-stroke accuracy of this passage, players should start the sixteenth notes off the string. This is an exception to the main rule of bowing technique which states that every bow-stroke is originated from the détaché, but Ramsey has found that doing so allows violists to match their phrasing with the main melody. ${ }^{78}$

\section{$\underline{\text { 4. Grouping Exercises }}$}

The following exercises help connecting or re-phrasing a melodic line that lacks direction or smoothness. Tuttle originally learned this idea of grouping the notes of the melody from Marcel Tabuteau. ${ }^{79}$ The concept aims to "make every note count, to mean something and have some intensity." ${ }^{80}$ As Burns explains, "Tabuteau used a numbering system for grouping notes together to enable phrasing beyond the dictates of regular bar lines. [Tuttle] found this useful for developing pacing, attaining an intuitive feel for musical direction and energy, and for learning how and why to organize notes within a phrase." ${ }^{81}$ Instead of using numbers, Ramsey teaches a method that helps organizing bow distribution. The main purpose was to help players smooth out a melody that lacked fluidity in its phrasing. Ramsey demonstrated this approach in a masterclass in which a student struggled with the phrasing at beginning of Schubert's "Arpeggione" sonata. In measure 11 of the first movement, a student was using too much bow at the beginning of the slurred B, C and D eighth notes in the second half of the measure. For that reason, she lacked sufficient bow when she reached the frog to create a crescendo and to make a smooth bowchange to the next down-bow. To save some bow while reaching the frog, Ramsey showed the

\footnotetext{
${ }^{78}$ Ramsey interview.

${ }^{79}$ Laila Storch, "Marcel Tabuteau," Oxford University Press, accessed October 14, 2018 , http:////www.oxfordmusiconline.com/grovemusic/view/10.1093/gmo/9781561592630.001.0001/omo9781561592630-e-0000027348.

This biographical entry shows some of Tabuteau's artistic highlights. His noticeable appointments include joining the faculty at the Curtis Institute of Music, where he introduced his phrasing system to generations of successful musicians.

${ }^{80}$ Burns, "Coordinated Action" 36.

${ }^{81}$ Ibid., 36.
} 
student how to stop the bow after each note and increase the bow-length of every eighth-note proportionally while saying an adjective with each of them. The words for each note were, "Less," "More," and "Most." This helped the student understand how to synchronize words with specific meaning to individual pitches in a phrase. This helped the student distribute the up-bow appropriately for the desired contour of the phrase. ${ }^{82}$ Another grouping method recommended by Ramsey groups slurred notes found in a single bow-stroke. For instance, while playing a oneoctave G Major scale with three notes per bow, she recommends that students play the first note of the scale at the frog and add a small pause before continuing. Then they should slur the next two notes on the same down-bow, dividing the rest of the bow evenly. Continuing the scale, the same procedure is done by starting at the tip for the up-bow. Once the student has played the scale using this pattern, they should repeat the scale without the stop. This grouping method helps distributing the bow evenly at the frog and tip while playing whole-bows. (See Figure 12.)

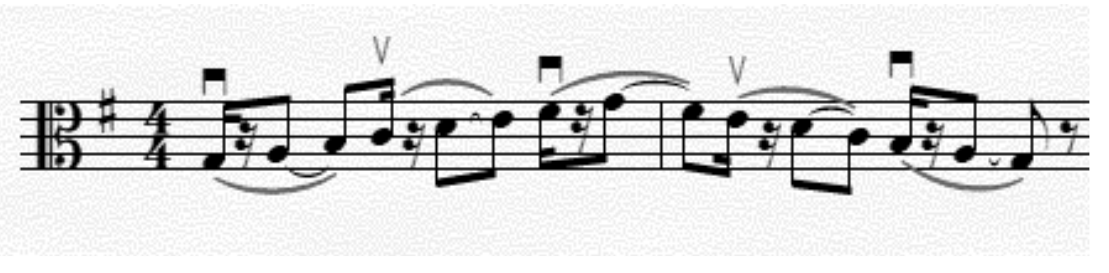

Figure 12. Grouping Method Used to Improve the Bow Distribution at the Tip and Frog of the Bow

\section{Recommendations on How to Prepare for a Successful Viola Audition}

As an orchestral violist, Ramsey has established an approach to practicing that allows her to perform consistently and successfully. She has four practice goals, which she calls

"Performance Pillars": "consistent intonation, perfect rhythm, beautiful sound, and clean

\footnotetext{
${ }^{82}$ Viola Masterclass: Lynne Ramsey, Viola, NaYeon Kim, viola, Amy Chiu, piano, Hayaka Komatsu, viola, Keisuke Nakagoshi, piano, Omar Shelly, viola, Deanna Badizadegan, viola, recorded the San Francisco Conservatory of Music, Music Library: Concert Hall, April 14, 2012, 2 videodiscs: sd. col.; 4 3/4 in. MPEG video, 2 hr., 11 min, https://libwvu-on-worldcat-org.www.libproxy.wvu.edu/oclc/883786181. All video recordings are fully cited in the bibliography section.
} 
articulation." ${ }^{83}$ The combination of these goals is constantly revisited through slow practice with the aid of a tuner, a metronome, and the practice techniques previously described in this chapter. This method has proven successful throughout Ramsey's career. In addition to the "Performance Pillars" that dictate her practice routines, Ramsey also believes that the decisive winning factors in a viola audition are the player's abilities to transmit their sense of musical line or direction in their performance of excerpts and their overall musicianship. ${ }^{84}$ Musicianship, she believes, can be learned by studying the score and by listening to recordings of orchestral works to understand how the viola line fits with the rest of the ensemble. Other viola performers, such as Robert Vernon, center their approaches to orchestral auditions similarly: Vernon believes that four "Performance Basics"-intonation, rhythm, tone, and bow articulations - are key to demonstrating a technical control of the instrument. Given that professional violists have mastery of these four basics, Vernon says that "to achieve a true artistic level," the player should also offer a personal interpretation of the orchestral excerpts. ${ }^{85}$

The process of preparation for orchestral auditions is a challenging task, and Ramsey recommends that every audition should be approached in a similar manner. The violist should audition without considering the ensemble's general sound characteristics and focus attention on their own musical preferences, thus offering a more convincing performance than by simply copying ensemble's sound. After a successful audition, violists can change their artistic decisions while rehearsing with the ensemble. ${ }^{86}$

Ramsey recommends that preparation for orchestral auditions should start at least six weeks prior to the audition date. The first four weeks should be dedicated to slow practice,

\footnotetext{
${ }^{83}$ Ramsey interview.

${ }^{84}$ Ibid.

${ }^{85}$ Orchestral Excerpts for Viola, with Robert Vernon (viola), recorded by Summit Records, Tempe: AZ, 1997, 1 audio disc: digital, stereo; 4 3/4 in., https://libwvu-on-worldcat-org.www.libproxy.wvu.edu/oclc/38983125.

${ }^{86}$ Ramsey interview.
} 
aiming to cover each "Performance Pillar." During the last two weeks before the audition, the violist should play through the audition repertoire every day. This process can be timeconsuming, but it helps the violist to be well prepared, which increases their confidence on stage. For the last week before the audition, the player should play and record the repertoire in its entirety every day so that they can review each "Performance Pillar," and ensure that their performance privileges the melodic line.

\section{What to Expect in and How to Keep an Orchestral Job}

\section{Professionalism and Following the Leaders}

Ramsey considers professionalism as an orchestral violist to be critical. The number of rehearsals and programs for a large ensemble like the Cleveland Orchestra can be overwhelming, and for that reason, mutual respect and teamwork among other musicians is a key to success. Orchestral violists are expected to follow the conductor, but depending on where a violist is seated, they might need to approach these directions differently to reach a consensus as a section. For example, in a section formed by twelve violas, the distance between the conductor and each of the six music stands differs greatly. To create a cohesive sound within the section, the last stands must play right on the beat with the conductor to avoid delays with the first stand. Furthermore, the stands furthest from the conductor should not lead or drag but should follow the conductor and the principal violist. ${ }^{87}$

Scavelli described the rotational seating system that the National Symphony Orchestra put into practice when he was a member of the orchestra. This system allowed every violist to have a chance to share a stand with every other member of the section, which provided an important opportunity during trial periods for new section members. After the trial period, the conductor would call all of the members of the viola section, asking their opinions of the new

\footnotetext{
${ }^{87}$ Ramsey interview.
} 
member. This would influence the new violist's future within the ensemble. ${ }^{8}$ As Rose writes, the responsibilities of a section member are "...not just about playing well with the other members of the section, but musically blending with the ensemble, and showing the highest standards of professional behavior and musical preparedness." 89

\section{Performance Practices: Be Prepared to Evolve over Time}

Ramsey’s collaboration with the Cleveland Orchestra has lasted for over thirty years. In 1989, while Christoph von Donányi was the artistic director of the ensemble, the orchestra's sound was, in Ramsey's opinion, "stiff and hard, and [every bow-stroke was] on the string."90 After countless engagements with other conductors, including the current artistic director of the orchestra, Franz Welser-Möst, one of the most noticeable changes that Ramsey has observed is the approach to pieces composed in between the $17^{\text {th }}$ and the $18^{\text {th }}$ Century. Historically informed conductors such as Nicholas McGegan ${ }^{91}$ and Jane Glover ${ }^{92}$ tend to request faster tempi and lighter bow-strokes than do previous generations of conductors. The Cleveland Orchestra's performance style for $17^{\text {th }}$ and early $18^{\text {th }}$ Century compositions requires a fast bow-speed and a conservative use of vibrato. For Classical pieces such as Mozart's symphonies, conductors often prefer a "light Romantic" performance style which demands a powerful sound from the strings, achieved through a heavy bow-arm and an active vibrato. ${ }^{93}$ For Beethoven, and especially his late works, the orchestra has been asked to play with a faster and more fluid pacing than in past

${ }^{88}$ Ramon Scavelli, in discussion with the author, May 2018.

${ }^{89}$ Rose, "An Orchestra Audition Preparation Handbook for Bass Players,” 32.

${ }^{90}$ Ramsey interview.

91 “Nicholas McGegan: Biography,” Nicholas McGegan, accessed September 18, 2018, http://nicholasmcgegan.com/biography/.

This source cites some of the accomplishments that McGegan has achieved throughout his career including his dedication to establish and promote period ensembles across America.

92 "Jane Glover: Biography," Music of the Baroque, accessed September 18, 2018, https://www.baroque.org/About/Performers/jane-glover.

This source cites some of the accomplishments that Glover has achieved throughout her career. These include collaborations with young professional musicians in the Aspen Music Festival, the Julliard School of Music and the Royal Music Academy.

${ }^{93}$ Ramsey interview. 
years. Performance approaches to Mahler have also changed over time, and the orchestra is now required to interpret a wide range of musical colors and to become familiar with each conductor's choice of timing, especially during transitions, prior to rehearsal. ${ }^{94}$

\section{Specific Duties and Recommendations for Viola Section Members}

To create cohesion and the blending of sound among the viola section, the section violist should follow the principal violist's playing and the conductor's beating and artistic decisions. By doing so, orchestral hierarchy is maintained, which prevents interpersonal conflicts and confusion in the section. If the principal player misses an entrance, for example, Ramsey considers that the chain of command might be briefly broken to keep cohesion within the section, but only if it is done discreetly: another player high in the hierarchy can point out the error to the principal. But if the principal misses entrances repeatedly, the person in charge of correcting this behavior should be the conductor. Through the conductor's actions, the chain of command is preserved, and this helps to avoid problems within the section. Even though Ramsey considers that, as an orchestral violist, she should aim to fulfill every conductor's request, not every request might enhance the overall sound of the section. That is why it can be problematic if a conductor asks the back of the section to lead with their sound: this alters the chain of command, unbalancing the normal practices of the section..${ }^{95}$ Earlier generations of violists such as Scavelli never experienced this situation, but in some rare cases throughout Ramsey's career, her section has been asked to do so. ${ }^{96}$

\section{Specific Duties and Suggestions for a Principal Violist}

When leading a viola section, Ramsey is fully aware that the rest of the viola players are sacrificing their individual sounds and musical ideas to create a unified sound, and her

\footnotetext{
${ }^{94}$ Ramsey interview.

${ }^{95}$ Ramsey interview.

${ }^{96}$ Ramon Scavelli, in discussion with the author, May 2018.
} 
understanding of this helps to create mutual respect between principals and section players. One common duty for principal violists is to interact with the other principal players to discuss any bowing preferences and to communicate any bowing, tempo, and articulation changes for the rest of the section made during rehearsals. If the entire viola section lacks cohesion, the principal violist should address the reasons for the lack during rehearsals; in terms of tempo, for example, the principal must be prepared to physically show the tempo to the rest of the section while playing. If a single violist is not fully engaged as a team player, however, Ramsey has often found it to be more useful to back off and allow that player to address their problems on their own. After playing with the Cleveland Orchestra, it became apparent to Ramsey that the uniformly high level of the viola section allows its members to play together by listening to one another and by watching the principal player.

Generally, the viola plays the role of connecting the lower and higher registers of the orchestra. This is occasionally a difficult task since these registers might have different concepts of tempo. In this situation, the principal should approach the conductor first to maintain the chain of command. Ramsey learned this lesson from Robert Vernon, who would approach the conductor politely during rehearsal breaks to discuss changes in bowings or concerns that were related to blending or synchronizing with other sections. ${ }^{97}$

In the next chapter, I discuss detailed information related to Ramsey’s pedagogy and playing techniques.

${ }^{97}$ Ramsey interview. 


\section{CHAPTER 3}

\section{RAMSEY AS A TEACHER}

In 2018, I conducted a personal interview and studied a recorded masterclass given by Ramsey at the San Francisco Conservatory of Music. This chapter draws on Ramsey's comments from those events.

Ramsey's teaching methods and techniques have been helpful to generations of violists. Her successful career as a pedagogue includes faculty appointments at recognized music schools and summer festivals, such as the Aspen Music Festival, and invitations to lead masterclasses across the US. The purpose of this chapter is to describe some of Ramsey's teaching methods. These concepts will be categorized throughout the chapter and illustrated with the aid of Ramsey's demonstrations.

In addition to the documents cited in Chapter Two, there are numerous other documents on the teaching methods of well-known violists. This literature includes violist Lauren Burns's DMA thesis, "Coordinated Action in String Playing: A Comparative Study of the Teachings of Paul Rolland and Karen Tuttle." Violist Susan Dubois's thesis includes material gleaned from her interviews with recognized viola and violin pedagogues Donald McInnes, Heidi Castleman, Samuel Rhodes, Dorothy DeLay and Karen Ritscher. ${ }^{98}$ These documents provide a context for the current chapter of this research document.

As a student, Ramsey was introduced to a variety of playing and teaching techniques that helped her create her own personal style. She still teaches some of these concepts to her students and has changed others over time. The performance techniques that Ramsey learned from Scavelli and Dawson were based on the so-called "Russian" style of playing. This technique

${ }^{98}$ Dubois, "Current Methods and Techniques," 175-190. 
requires a very active right hand to perform off-the-string bow-strokes, which troubled Ramsey. She felt that these teachers required her to concentrate too much attention on the hand and fingers of her right arm to play off-the-string bow-strokes, which she believed was not a successful approach. However, once Ramsey started studying with Tuttle, Tuttle helped her simplify her right arm technique. In contrast with the Russian approach, Tuttle taught that every bow-stroke originates from the détache bow-stroke. This is just one example of how Ramsey's approaches to playing and teaching have evolved over time.

\section{Shifts in Ramsey's Teaching Styles Over Time}

Even though Ramsey has taught viola students throughout her entire career as a professional musician, her teaching style shifted greatly after studies with Tuttle. Once she finished her education in New York and moved to Pittsburgh to become a member of the PSO, she remembers that her teaching style lacked positive reinforcement towards her students. ${ }^{99}$ She often concentrated her attention more on the weaknesses of her students' playing than encouraging their strengths and abilities. She found that this method only addressed performance issues and avoided comments on her students' strengths as players, which can eventually wear down students' confidence. After studying with Tuttle, Ramsey changed her approach to her teaching, including new teaching values such as "the beauty of the individual." 100 This method provided for understanding each student as an individual and helping them develop a personal style that brought out the individual qualities of every student. Once Ramsey and her students identified these qualities, the next step was for Ramsey to figure out ways in which to develop every student's individual skills as much as possible. She realized that she would need to be as committed to her students as they were to themselves. This worked both ways: if a student did

\footnotetext{
${ }^{99}$ Ramsey interview.

${ }^{100}$ Ramsey interview.
} 
not come prepared for their lesson, Ramsey would rather protect her time and finish the lesson early.

\section{Posture and Balance of the Instrument}

Posture and balance of the instrument is vital to Ramsey's teaching approach. Just as she was taught by Tuttle, Ramsey advocates for maintaining an open and flexible posture while playing, which should resemble a natural walking posture or the posture one would take when meeting someone in a comfortable situation. ${ }^{101}$ She believes one should, "stay open, push out [while playing down-bows], ... and all of your up-bows...you are going be as tall as you can be.” In order to balance the viola with good posture, she always keeps three points in contact with the instrument: the left hand, the left shoulder, and the collarbone. In situations such as playing a soft or challenging passage, a violist might hunch over while playing, which unbalances these three points of contact. To avoid this, Ramsey recommends that players keep a steady posture, which also transmits confidence to the audience, and allows for space in between the internal organs. She reinforces the importance of maintaining a good balance and posture by saying: "when you are playing for people, you want to be saying. ' $\mathrm{Hi}$, I have something to say to you, and I am not afraid to say it. I'm just going to do it'." This attitude helps her and her students to connect with the public confidently. ${ }^{102}$

Ramsey's body posture while standing requires springy knees, with the right leg situated slightly more forward than the left one to allow the weight of the upper body to shift freely from one leg to the other. (See Figure 13.) The upper body weight should rest on the hips while keeping the shoulders low and relaxed, and the chest naturally open. This set-up offers physical flexibility while performing and avoids injuries from performing hunched over or with tight

\footnotetext{
${ }^{101}$ Burns, "Coordinated Action,” 40, 42.

102 Viola Masterclass: Lynne Ramsey, Viola.
} 
muscles. ${ }^{103}$ For a seated playing position, Tuttle taught Ramey to place herself on the front of the chair, granting room for motion in the hips, but Ramsey's preference is to sit on the back of the chair. (See Figure 14.). Because of long and tiring rehearsals with the Cleveland Orchestra, Ramsey had to find other ways of sitting. This back-of-the-chair position allows the player to vertically align the weight of her upper body to rest on her hips while keeping the upper back away from the chair. Finally, she recommends keeping the knees active and unlocked, in part so as to be able to stand up with minimal effort. ${ }^{104}$

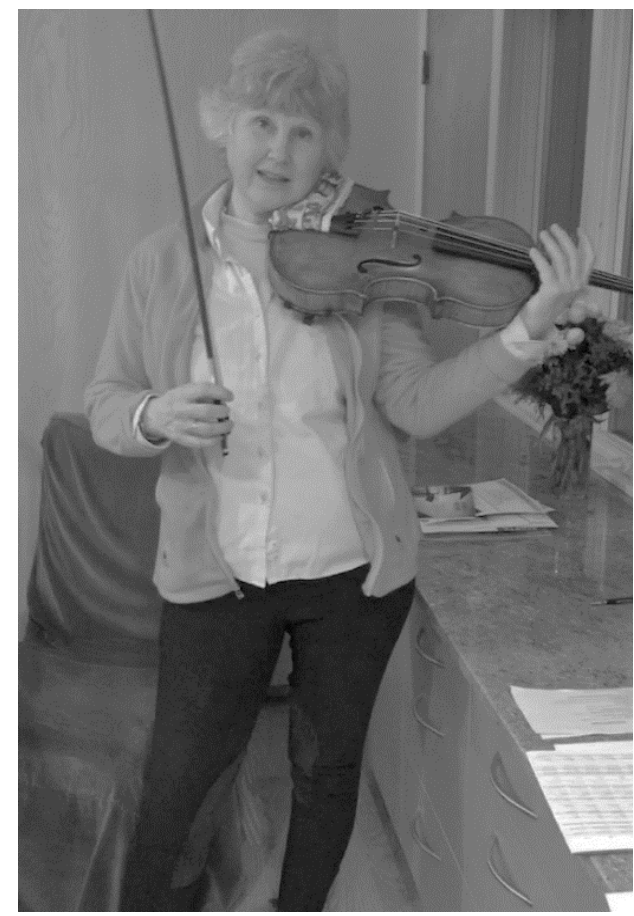

Figure 13. Body Posture while Standing

${ }^{103}$ Dubois, "Current Methods and Techniques," 48.

${ }^{104}$ Ramsey interview. 


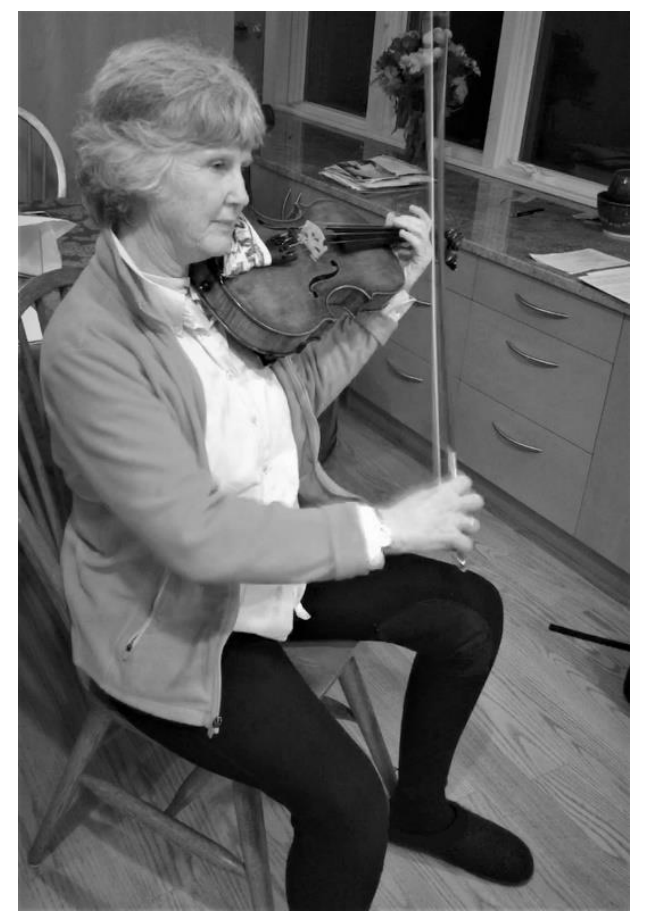

Figure 14. Playing Position while Seated

\section{The "Coordination" Technique}

The "Coordination" Technique is a concept originally created by Tuttle, who describes it as "the relationship between the horizontal movement of the bow and the movement of the neck, shoulders, chest, and pelvis. This physical coordination affects the musical phrase, the spacing of notes, and the dynamics." 105 The "Coordination" technique has proven to be very beneficial to students who play with excessive physical tension. This tension might prevent them from fully express their musical ideas, and with the use of this technique, students release some of their physical tension and are able to better communicate their musical ideas. ${ }^{106}$ Tuttle's method has

\footnotetext{
${ }^{105}$ Karen Ritscher, “An Interview with Karen Tuttle,” American String Teacher, vol. 43, no. 4, 14 December, 2017 : 89, https://libwvu-on-worldcat-org.www.libproxy.wvu.edu/oclc/7260399753.

${ }^{106}$ Parker, “A Survey of Viola Teachers' Perceptions,” 24.
} 
been widely discussed in research documents, journal articles, and workshops such as the Karen Tuttle Viola Coordination Workshop. ${ }^{107}$ Here, I discuss this method from Ramsey's perspective. Depending on the needs of a specific student, Ramsey applies this concept to help solve their posture and playing problems. Ramsey teaches her students to "[integrate] your natural body movements into playing the viola and to your breath." ${ }^{108}$ In other words, she attempts to reduce physical tightness by incorporating the natural breath and response of the body into players' performance stances and practices. This organic relationship provides an approach to viola playing that allows physical actions to support a musical idea. The basic right-arm technique of this approach relates to the natural lifting and dropping motion of the right arm, and the "Coordination" approach teaches that both the right arm and the left hand should cooperate and use synchronized movements.

Breathing naturally is an important part of the "Coordination" technique. Breathing out before playing lowers the shoulders and centers the playing set-up posture. Ramsey has learned that students perform better if her instructions to them are clear and practical. Students are more prone to tense up if the teacher suggests very specific and complicated instructions. ${ }^{109}$ That is why simple recommendations, given one at a time, such as breathing out before starting to play, can help reduce a performer's anxiety and help them combine both the right and the left arms together. For students new to the idea of thinking about breathing as part of playing or who needed to refresh this concept, Ramsey recommends a specific exercise. Instead of simply telling her students to breathe out before they play, she asks them to say "HAH" out-loud before

\footnotetext{
${ }^{107}$ Laurie Niles, "Playing Viola with Ease: Karen Tuttle's Concept of 'Coordination'," Violinist.com, June 23, 2016, accessed September 24, 2018, https://www.violinist.com/blog/laurie/20166/19585/.

${ }^{108}$ Ramsey interview.

${ }^{109}$ Viola Masterclass: Lynne Ramsey, Viola.
} 
playing. ${ }^{110}$ The student should start the breathing motion from the stomach and release the abdomen while saying "HAH." 111 This also relaxes the shoulders and re-centers the body posture. Furthermore, saying "HAH" in the tempo of the piece helps coordinate both arms naturally. Breathing out before playing in exposed situations such as an audition, a competition, or an exposed performance is especially advised to combat stage fright. ${ }^{112}$

\section{Body Tension Awareness}

Ramsey considers body awareness to be a fundamental component for a performance, providing a better understanding of how to play efficiently and healthily. For her, the "Coordination" technique has proven to be an element that contributes positively to her performances because it provides a strong playing foundation. As a teacher, Ramsey has taught students who suffered physical tightness from stage fright. In one instance, Ramsey worked with a student who lifted her right shoulder as a result to performance anxiety. The tightness Ramsey observed in the student's right shoulder caused abrupt bow changes, which prevented fluidity in lyric passages. By lifting her shoulder, the natural weight and flow of the student's right arm was compromised. Ramsey leaned on the student's risen shoulder while she was performing, and the student, becoming aware of her own body, eventually lowered her shoulder. ${ }^{113}$ If a student is immune to this hands-on technique, Ramsey asks the student to exaggerate the problem causing poor playing. In this case, she might ask the student to "put your shoulder as high as you can. Now breathe out, and play." 114 She would repeat this process until the student released the upward tension to allow a natural motion from the right arm. In both of these approaches, Ramsey shows how she advocates for teaching in such a way that allows students to reach their

\footnotetext{
${ }^{110}$ Viola Masterclass: Lynne Ramsey, Viola.

${ }^{111}$ Ramsey interview.

112 Ibid.

${ }^{113}$ Viola Masterclass: Lynne Ramsey, Viola.

${ }^{114}$ Ramsey interview.
} 
highest personal level of performance with the aid of specific techniques to reduce physical tightness and to allow fluidity in their motions.

\section{Right Arm Exercises}

\section{The Basic Right-Arm Motion}

Ramsey has compared the basic up- and down-bow motion to the forehand motion made in tennis. She compares the natural swing of the right arm observed in tennis with pushingthrough on a down-bow and pulling on an up-bow. To demonstrate, she swings her right arm without her bow, finding the limits on both ends of this motion, letting her arm continue its natural course behind the back and above the head. ${ }^{115}$ Once this gesture feels natural, the next step is to find a similarly natural up and down motion with the bow. Ramsey centers her rightarm technique on what Tuttle learned from Demetrious Constantine Dounis (1893 - 1954), that "the basis of all bow technique is solely the simple and accentuated détaché." 116

The following illustrations clarify the shape of Ramsey's right hand while bowing. (See Figures 15, 16, and 17.) This shows her own personal bow-hold; she does not believe in a onesize-fits-all bow-hold. She prefers to let the students find their own right-hand shape because each student possesses a unique shape of the hand, and what Ramey does might not work for all of her students. Instead, the most important piece of information that she shares with her students while teaching them about the bow-hold technique is to remember to start the bowing motion from the bigger muscles: the "[right-] hand [must] react to the big muscle groups as they push and pull the bow." This means that the hand should follow the motion that the right arm draws

\footnotetext{
115 Viola Masterclass: Lynne Ramsey, Viola.

116 Demetrious Constantine Dounis, The Artist's Technique of Violin Playing: A New Scientific Method for Obtaining, in the Shortest Possible Time, an Absolute Mastery of the Higher Technical Difficulties of the Left Hand and of the Bow, op. 12: 5, https://libwvu-on-worldcat-

org.www.libproxy.wvu.edu/search?queryString=no:681855949\&databaseList=2375,2264,2572,2263,2262,2261,328 $\underline{4,2260,2281,2328,2237,2259,3205,2268,3203,2267,3201,2277,638,3209 \& \text { scope=\#/oclc/681855949. }}$.
} 
while bowing. Therefore, depending on the right-arm shape of the violist; the right hand should adjust accordingly while bowing. Ramsey recommends holding the bow at the frog with curved and relaxed fingers and a slightly curved wrist as shown in Figure 16. The fingers touch the bow while playing in the middle of the bow and her fingertips maintain a steady contact with the bow even as her wrist naturally straightens, as shown in Figure 17. At the tip, due to the extended position of the arm, the wrist bends downward while the fingers retain contact with the stick, as shown in Figure 18. At the frog, the elbow initiates the movement of the upper-right arm. When moving from the lower- to the upper-half of the bow, the elbow lowers and extends forward. Similarly, when moving from the upper- to the lower-half of the bow, the elbow rises and contracts. $^{117}$

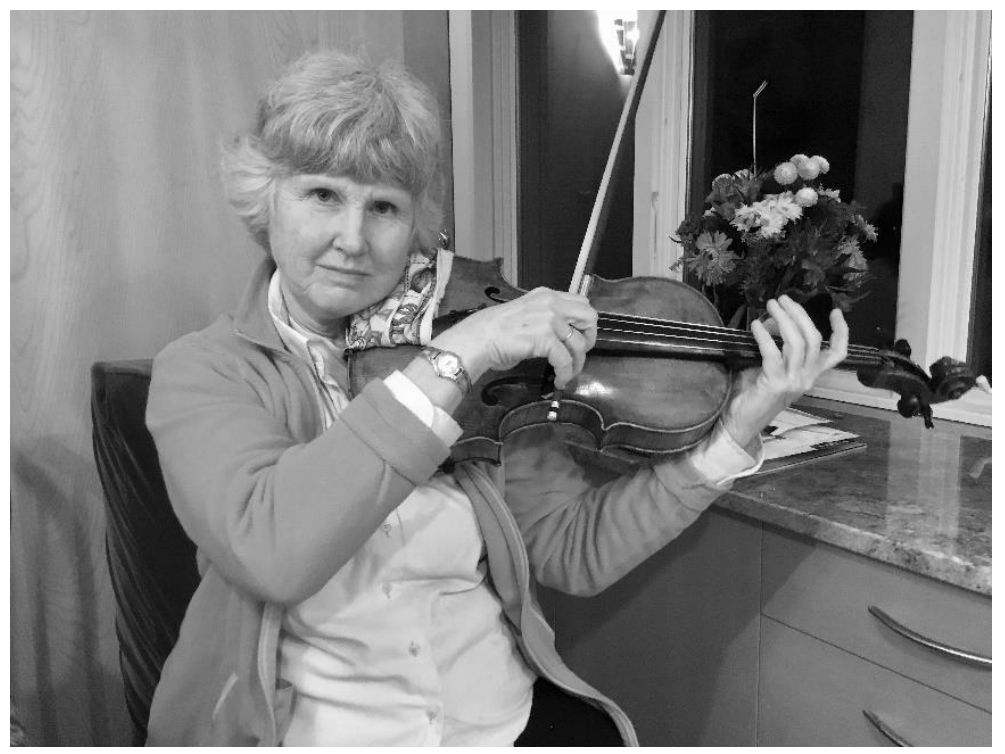

Figure 15. Playing Position while Bowing at the Frog of the Bow

117 Viola Masterclass: Lynne Ramsey, Viola. 


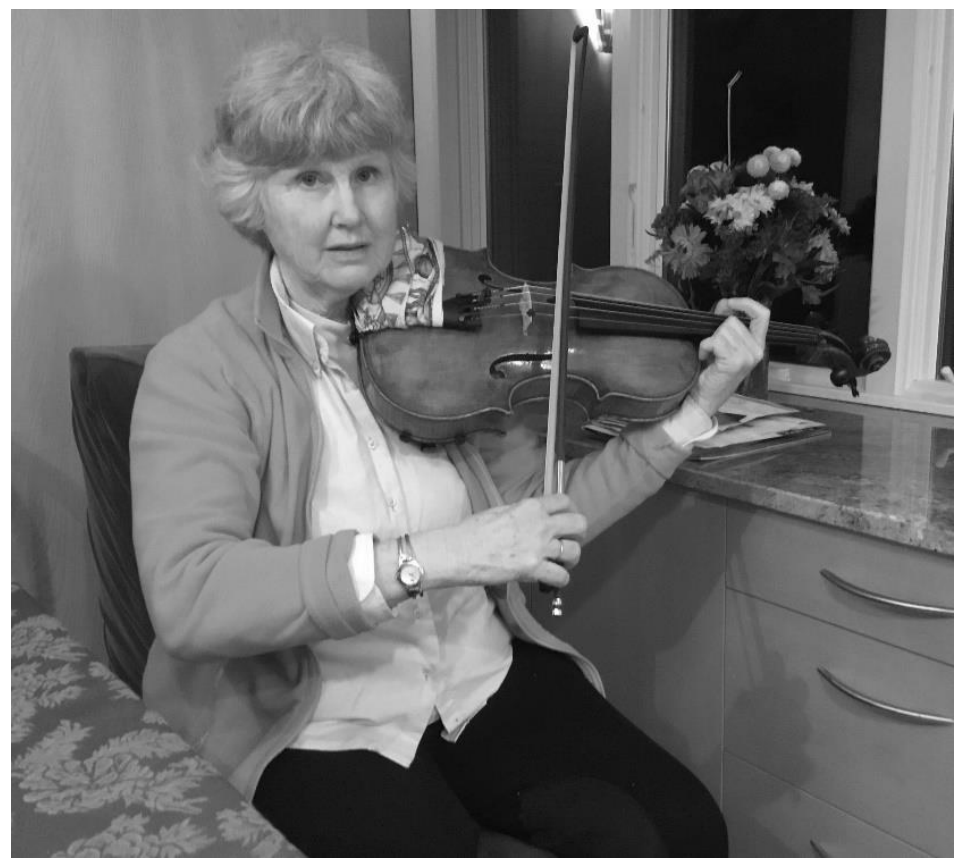

Figure 16. Playing Position while Bowing in the Middle of the Bow

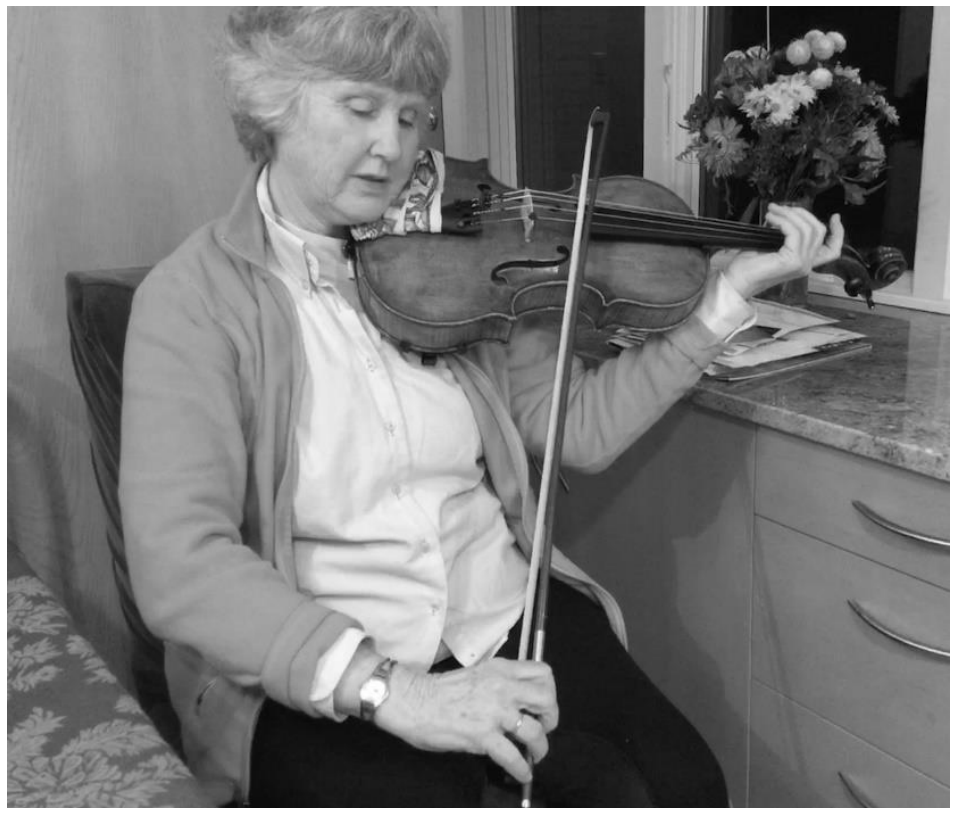

Figure 17. Playing Position while Playing at the Tip of the Bow 


\section{The "Rocking Swing" or "Rocking Baby" Exercise, and the "Initiators"}

Ramsey relies heavily on simple and efficient exercises and concepts that help her students to improve their playing skills. One of these exercises is called "Rocking Swing" or "Rocking Baby." It consists on playing several short up- and down-bows at the frog, of equal length. This exercise introduces her students to the idea of moving the right-arm muscles as one unit at the frog. Only the right-arm should move up and down during this exercise, while keeping the shape of the arm as steady as possible. To move the arm as one unit, Ramsey recommends imagining that the bowing motion starts from the right side of the upper back. This part of the back is what she calls the "Right Wing." By picturing the start of the bowing motion in the "Right Wing," the violist can move the right arm as one unit while practicing the "Rocking Swing." Furthermore, she reiterates the importance of breathing naturally throughout this exercise in order to release muscle tightness in the right arm. Once the violist can play the "Rocking Swing" naturally, Ramsey teaches the "Initiators," another technique she learned from Tuttle. The "Initiators" is a concept that introduces the idea of breathing out prior playing a bowstroke. When the player breathes out, the right-arm muscles release the tension from holding the bow before playing and the player is able to land the bow on the string more easily. This concept improves the sound quality of the beginning of the bow-stroke. This technique requires an exhalation during the preparation pickup that precedes the sound produced by the bow. In other words, the exhalation precedes the player's putting the bow on the string prior to bowing in a similar manner as an orchestral conductor would prepare an entrance from silence. The type of exhalation depends on the nature of the preceding music: fast melodies require a short and active exhalation pickup, and slow melodies require a slow and relaxed exhalation pickup. By breathing 
out prior to playing, the violist also reduces the risk of injuries because they have trained their right-arm muscles release all tension before playing. ${ }^{118}$

\section{The "Re-Pull" Technique}

Ramsey originally learned this technique from Tuttle, and she teaches it to her students as well. Burns describes the as "Re-Pull" as "a melting sensation accompanied by a release in the lower back, knees and pelvis and an exhalation on the syllable "ha."119 Burns adds that, "the right-hand rolls towards the pinky side (supination) during the "re-pull," found by stopping the bow at the lower 1/3 and rebalancing the hand with a tug-of-war in the opposite direction." 120 For Ramsey, this technique does not advocate for an independent motion in the right hand, as Burns describes it, but it concerns the release of tension in the upper back. In Ramsey's version of the "Re-Pull" she begins in middle of the bow and recommends releasing the upper-back muscles while exhaling and drawing the bow downwards. This helps increase the power of the bow. This exercise can be practiced on both up- and down-bow motion. The increased arm weight during the "Re-Pull" can be observed in the position of the right arm, which is lowered as the performer reaches the middle of the bow. This additional weight also slows down the bowspeed. Acoustically, the increase of weight and the slowdown of the bow offers a fuller sound quality originated from pulling the string. In Ramsey's words, "the best sound [is produced] when you are pulling the string." ${ }^{121}$ During the "Re-Pull," the weight of the bow is distributed horizontally on the bow, which provides an unforced sound in the middle of the bow.

\footnotetext{
118 Viola Masterclass: Lynne Ramsey, Viola.

119 Burns, "Coordinated Action," 59.

${ }^{120}$ Burns, "Coordinated Action," 59.

${ }^{121}$ Ramsey interview.
} 


\section{An Overview of Bow-Stroke Techniques}

Most of what Ramsey learned in her right-hand technique was taught to her by Tuttle, who had learned from Primrose. Burns describes Tuttle's right-hand technique as a "technique in which the right hand should fall naturally as if not worried about holding the bow. [Then, following this first step, $\mathrm{t}$ ]he thumb and middle finger create a circle to hold the bow with the other fingers acting as support." ${ }^{122}$ Even though they provided specific instructions on how to hold the bow, Tuttle and Ramsey respected the individuality and uniqueness of each student. In fact, Ramsey's and Tuttle's bow holds are slightly different. Tuttle's right-hand shape extends the index finger at the frog. In contrast to this, Ramsey has a rounder shape in her fingers, including the right index finger. This is apparent in the illustrations of Ramsey's right hand in this chapter (see Figures 16, 17 and 18), and also in earlier pictures taken during the concert in Beijing, in 1989 (see Figure 3), which overlapped with her time as a Tuttle student. Even though this might seem to be a small detail, it shows that bow holds can be adapted to fit the needs of each violist.

To help students simplify their right-hand setups, Ramsey often offers analogies for the technique required for the bow-hold and shapes found in common situations or popular knowledge. In one masterclass, she made an analogy about the right-hand shape and the rounded structure of an antique Roman bridge. For her, a slightly arched shape on the right hand provides a strong foundation for any bow-stroke and transfers the weight from the right arm to the bow efficiently. ${ }^{123}$ Another analogy that Ramsey uses to help students understand this concept is one in which she refers to the shape of the right hand while opening a lid. To twist a lid in the most efficient way, she says, you would hold a curved shape of the wrist and hand to provide more

\footnotetext{
122 Burns, "Coordinated Action," 65.

123 Viola Masterclass: Lynne Ramsey, Viola.
} 
leverage. On the contrary, flattening the hand while opening the lid would contribute to increased tension and reduced strength in the hand. Similarly, while playing, a flat hand at the frog or in the middle of the bow creates more unwanted tension and less leverage than a rounded shape in the hand and wrist. Ramsey considers to be crucial that the right-hand thumb should serve to adjust the angle formed between the fingertip and the touching side of the frog. At the frog, Ramsey recommends keeping the right-hand thumb naturally bent inwards, and while travelling to the tip, extending it progressively until creating a straight line. ${ }^{124}$

Ramsey usually keeps her right-hand fingers and fingertips close together on the bow without adding additional motions coming from the fingers. This helps her achieve a constant sound at every part of the bow and reduces any inefficient wrist or finger action while bowing. Any alteration coming from the right hand and wrist should only occur when the hand finds resistance while travelling from one part of the bow to another. The right hand should never be stiff or concrete, but instead flexible and held in shape that improves the stability of the overall bowing technique. Also, by positioning the bow nearer to the bridge, performers can produce a more sustained and unforced overall sound. ${ }^{125}$ In order to move the bow towards the bridge, the player should shift the angle of the bow stick away from the bridge, reducing the surface of bow hair touching the string. Then, while keeping the same bow angle, the player should move the bow closer to the bridge using the right arm, wrist and fingers. This change of placement of the bow, which reduces the string length between the bow hair and the bridge, increases the tension of the string at the point of contact with the bow while playing. This increased tension requires greater arm weight, and, as described by Ramsey, the violist should only move the bow closer to the bridge when also adding arm weight, which produces an unforced sound. Ramsey often uses

\footnotetext{
${ }^{124}$ Ramsey interview.

125 Burns, "Coordinated Action," 68.
} 
an analogy that helps elucidate this concept in which she compares viola playing with driving different types of vehicles. In her opinion, a student playing with a fast bow speed and with minimal weight on the bow and far from the bridge was "driving a sports car," when she wanted him to "drive a truck" instead. ${ }^{126}$

For teaching other bow-strokes, such as martelé, Ramsey finds it to be useful to remember that the big muscles found on the right side of the upper-back are the initiators of the movement, and the rest of the muscles found on the right arm react from it. As she describes it, returning to her driving analogy, the muscles that act as initiators would be the ones sitting in the driver's seat, and the rest of the muscles would be the ones in the passenger's seat. ${ }^{127}$ The martelé bow-stroke requires an accentuated beginning, which involves a heavier weight with the bow than for détaché. At the tip of the bow and prior to the start of the bow-stroke, the arm weight needs to be transferred to the dorsal side of the right hand to provide control and accuracy during the accent. Also, for both up- and down-bows, the elbow should be unlocked to allow a fluid bow-stroke motion. By keeping the elbow unlocked during a down-bow, the right arm can extend to and form a straight line, which enables better playing in the upper-half of the bow. Similarly, by allowing the elbow to contract, the right hand can better control the lower-half of the bow. To help understand the right-hand technique for the up-bow martelé bow-stroke, Ramsey compares it to scooping ice cream or digging soil with a shovel. Once the player reaches the tip, prior to the accent, both the right hand and wrist lower to provide more leverage (See Figure 18.)

Ramsey also teaches specific techniques for spiccato and sautillé bowing. She holds that it is paramount to remember that every bow-stroke originates from the détaché bow-stroke, and that

\footnotetext{
126 Viola Masterclass: Lynne Ramsey, Viola.

${ }^{127}$ Ramsey interview.
} 
the off-the-string strokes should follow this same procedure. This allows for consistency and ease while playing any bow-stroke.

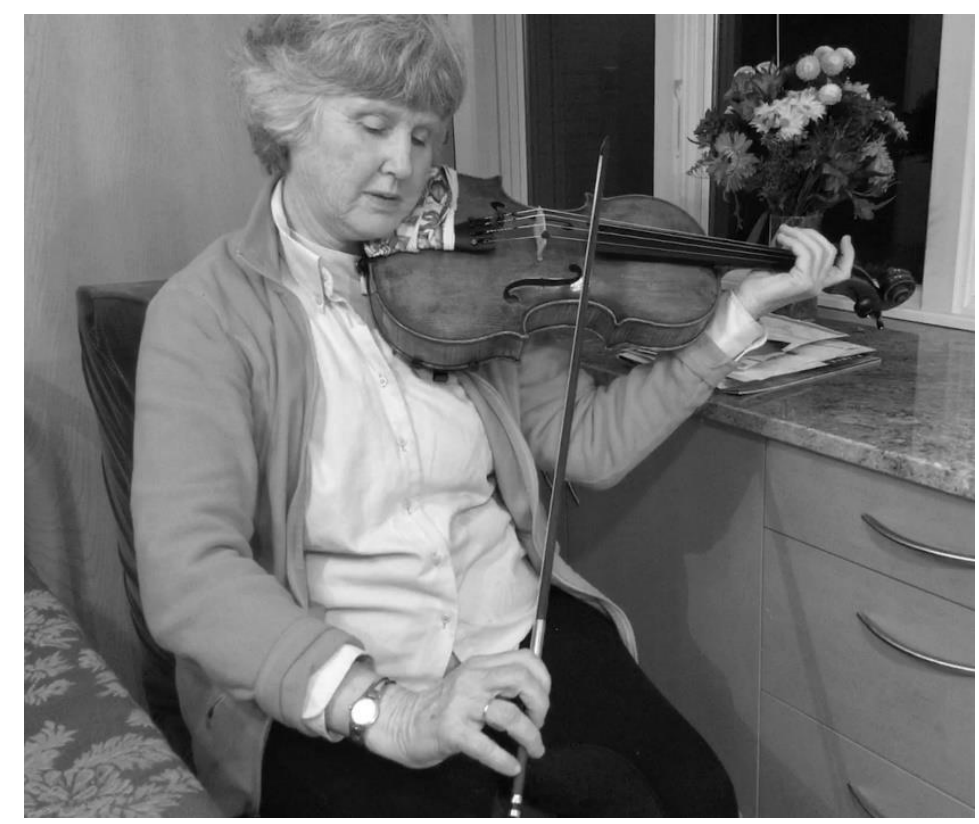

Figure 18. Lowered Position of the Right-Wrist and Hand Prior to Up-Bow Martelé Bow-Stroke

Her very effective approach for learning how to play spiccato starts by having the student play short détaché bow-strokes in the upper-half of the bow, and slowly move the bow towards the frog. An appropriate speed for this exercise would be to play sixteenth notes at 90 beats per minute. This should be practiced without making any adjustments to the right arm to force the bow to bounce; eventually, the bow should start bouncing on its own. Usually, slightly below the middle of the bow is the most appropriate placement for a natural spiccato. Both spiccato and sautillé strokes should be approached in a similar manner. The only difference would be that the sautillé bow-stroke requires a faster bow-stroke and the bow should be slightly further away from the frog. 
In addition to Ramsey's suggestion that every bow-stroke should originate from a détaché base, she suggests that in order to be efficient and to avoid injuries, players should remember that for bow-strokes that require the use of the entire bow, the intensity of motion from the bigger muscles found in the upper back must be greater than in the smaller muscles found in the arm. This helps to produce a healthy sound and to reduce injuries in smaller muscles found in the right arm, hand, and wrist by reducing the intensity with which they are used during the bow-stroke. This does not mean that the smaller muscles will be inactive during these bow-strokes, but that they continue the motion that the bigger muscles already started. Furthermore, the weight of the upper back muscles is transferred to the right arm, wrist, hand, and fingers to reach the string through the bow. This helps to create an organic and structured motion in the right arm while playing long bows, which in turn, produces an unforced and natural sound across the bow. Ramsey also believes that the shorter the bow-stroke, the less motion from bigger muscles is required. For instance, the motion for a tremolo bow-stroke at the tip should be mostly visible in the hand, wrist, and fingers, without a visible contribution from any other larger set of muscles. ${ }^{128}$

\section{Circular Motions in the Right Arm}

Ramsey learned from Tuttle the concept of creating rounded motions in the right arm to reduce unnecessary stiffness and offer players a better chance of producing a connected and natural sound while bowing. Examples in which a violist might struggle with connectivity can be found between or at the end of lengthy notes or slurs, or while changing bow directions. Figure 19 shows the circular motion that the bow follows during bow changes. With this exercise, the player creates a rounded contour of the bow that resembles a " $\infty$ " shape, which helps to create a

\footnotetext{
${ }^{128}$ Ramsey interview.
} 
smooth bow-change. ${ }^{129}$ More specifically, this motion elevates the hand slightly while changing from down- to up-bow and also lowers it while changing from up- to down-bow. This technique is useful for slow bow-strokes, but it is not recommended for bow-strokes such as spiccato, which require a quicker right-arm motion.

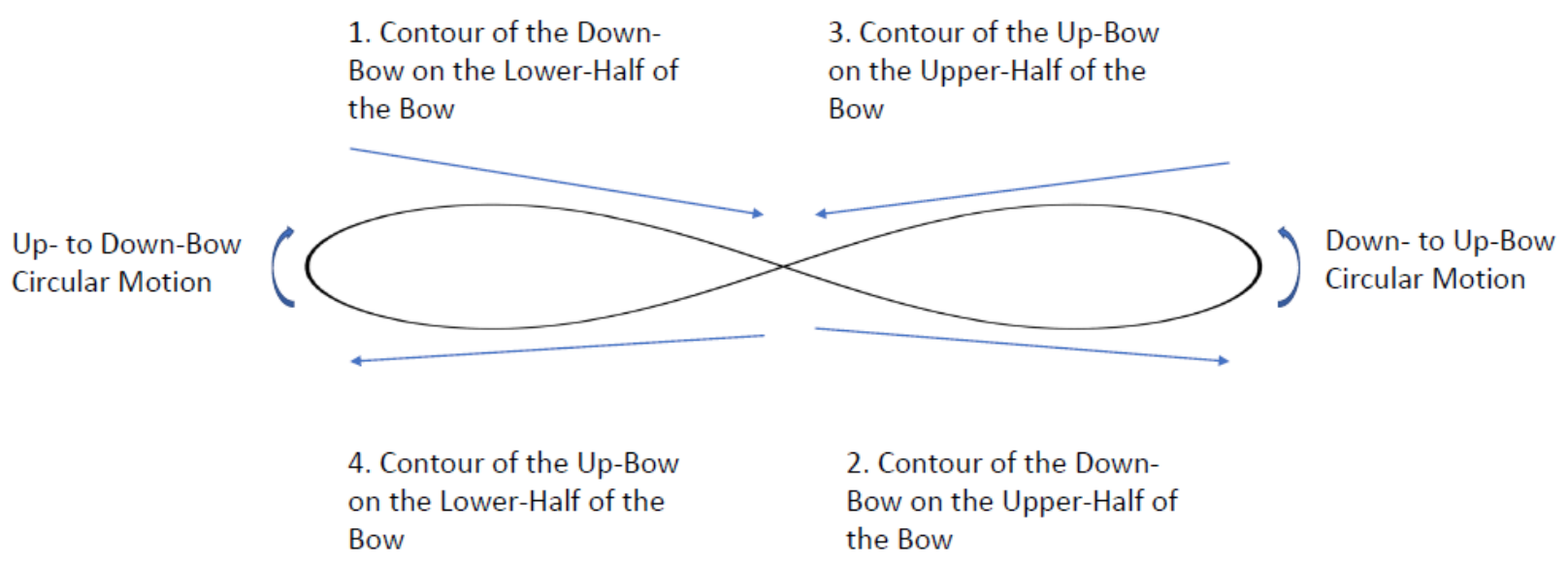

Figure 19. Contour of the Bow while Adding the Use of Circular Motion for a Smooth Bow-

\section{Change}

To avoid flat or broken musical lines, Ramsey recommends several techniques to her students that include a circular motion, such as the "Energizers." To help students understand this exercise, Ramsey adds an additional step prior to the "Energizers" to introduce this technique. ${ }^{130}$ She first has students divide a down-bow into two equal halves and add a small "Crutch" or pause in the middle of the bow. Then, for the full "Energizers" exercise, she had students add a rounded motion after the "Crutch" which resembles a U-shape draw in space by the elbow. The advantage of stopping the bow in the preliminary step of performing the "Energizers" exercise is that the student is able to separate the standard down-bow motion and

${ }^{129}$ Viola Masterclass: Lynne Ramsey, Viola.

${ }^{130}$ Viola Masterclass: Lynne Ramsey, Viola. She demonstrated this technique in a masterclass to a student who was struggling while connecting a melody naturally. 
the "U" shape needed for the "Energizers." This helps make the right elbow follow the natural contour required for the down-bow motion and assists one to perform the "Energizers" at the specific location of the bow. Furthermore, when the "Energizers" are practiced without the "Crutch," this technique helps to connect the lower and upper halves of the bow smoothly. For Ramsey, the initiators of this motion are the large muscles found on the right side of the upper back, which transmits the gesture to the upper right arm and to the right elbow. The "Energizers" exercise calls for players to lower and raise their right elbows from their usual planes, which alters the weight of the bow on the string and helps improve the stroke in the middle of the bow. Another situation in which the "Energizers" might be appropriate to facilitate a smooth connection is found in notes that have dots or ties attached to them. This aligns with Ramsey's belief that "[the] musical parts of the notes are the dots and the ties." The use of the "Energizers" technique in notes with dots or ties would take place between the note and the dot or tie. By doing so, "the note isn't just static," but provides direction to the melody. A way to check if this method is effective is by recording and listening to the recording to make sure that "a note ... either goes somewhere, or it goes away from somewhere," avoiding a flat line. ${ }^{131}$

While playing at the tip of the bow, the right arm must transfer a higher amount of weight to the bow than in any other location. This is in part due to the required extension of the right arm and the distance of the right hand from the strings when reaching the tip of the bow. To avoid unwanted tension in the right arm, Ramsey recommends that while playing a down-bow at the tip one should release the chin upwards while completing the down-bow and starting the upbow, also known as "following through" or "pushing through." ${ }^{32}$ When the player releases the neck during bow changes, their right arm is able to connect with the new bow naturally. Ideally,

\footnotetext{
${ }^{131}$ Viola Masterclass: Lynne Ramsey, Viola.

${ }^{132}$ Ramsey interview.
} 
the bow acts as an imaginary rubber band that is connected to the neck and right hand while reaching the tip of the bow. This rubber band is stretched by the right hand and neck while reaching the tip, and then it releases back to its tensionless position when it moves away from the tip.

\section{The "Pushing-Out" and "Hinging-In" Technique}

Ramsey teaches the following two bowing techniques frequently to simplify other bowing techniques to her students. ${ }^{133}$ These two techniques are what she calls "Hinging-In," and "Pushing-Out." "Hinging-In," which resembles the hinge of a gate, is the motion of the elbow during the up-bow, and "Pushing-Out," is the forward extension of the arm during the downbow. Ramsey learned to use these images from Tuttle. If practiced correctly, these techniques help enable a player to keep their sound constant while playing an up- or down-bow. One way to see whether these two techniques are being employed successfully to help improve sound production is by checking to see if the contact point of the bow on the string changes while the player makes these motions. If the "Hinging-In" and "Pushing-Out" techniques alter the contact point on the string, the consistency in the sound will also be altered. To ensure consistency in the sound, the contact point should stay the same while practicing these techniques. To perform the "Push-Out" technique, the right arm moves gradually further forward and away from the body during the course of a down-bow. For the "Hinge-In," the right arm gradually closes to a more acute angle and raises up as the player when approaches the frog from the tip or middle of the bow during the up-bow. One advantage of raising the arm while approaching the frog during the up-bow is that part of the arm weight is lifted from the string, which helps to produce an unforced sound. The "Pushing-Out" technique is especially beneficial for a player who hunches

\footnotetext{
${ }^{133}$ Ramsey mentioned these concepts in a recorded masterclass cited in the bibliography section of this research document, and during the interview with the author.
} 
over or lifts up their right shoulder while playing at the tip of the bow. ${ }^{134}$ Ramsey recommends keeping the right shoulder down, the back straight, and extending the right arm forward on a down-bow at the tip. When approaching the frog, she recommends executing the "Hinge-In." In addition to raising and slightly retracting the elbow, the "Hinge-In" also requires the player to make a slight bend in the right wrist, hand, and thumb, with a lowered right shoulder. ${ }^{135}$ Thus the weight of the bow at the frog is reduced, and the thumb is able to naturally bend inwards. When the bow moves to the tip, the player can extend their thumb progressively until they have created a straight line formed by the thumb. An example in which this is useful is the beginning of the first movement of Carl Stamitz's Viola Concerto, which contains a sequence of two notes that require a quick re-take at the frog. ${ }^{136}$ The "Hinge-In" bowing technique allows this sequence to incorporate a circular and continuous motion in the down-bows, and a better approach for each note. Another exercise that Ramsey teaches to create player awareness and flexibility while hinging-in is called "Smelly Twinkle." ${ }^{137}$ Ramsey learned this exercise from her daughter's Suzuki teacher; it asks the player to bring the right thumb close to the nose after playing every two notes of the song "Twinkle, Twinkle, Little Star.” Ramsey asks students to play two notes of the song at a time and then to place the right thumb closer to the nose while breathing in for two beats. ${ }^{138}$ Even though this exercise might sound childish, it facilitates the production of an unforced sound at the frog while keeping the bow-hold consistent during the re-takes.

\section{Left Hand Exercises}

As a general principle, Ramsey teaches that the left hand should be flexible to move freely across from any string and to shift to a new position smoothly. To help a student

\footnotetext{
${ }^{134}$ Viola Masterclass: Lynne Ramsey, Viola.

${ }^{135}$ Ramsey interview.

${ }^{136}$ Viola Masterclass: Lynne Ramsey, Viola.

${ }^{137}$ Ibid.

${ }^{138}$ Ibid.
} 
understand the main principles of the left-hand technique, Ramsey bases her technique in the following elements: "Rubbery Fingers," "Plop and Slur," (and) double stops thirds and octaves. By "Rubbery Fingers," Ramsey means that the left-hand fingers should be active and flexible, enabling them to drop quickly to the fingerboard. This requires a quick response from the base knuckles, which provide clear and accurate articulations in the fingertips. Then, the "Plop and Slur" method, which I have discussed above, can be used to improve the quality of the vibrato. This technique helps a student to find left-hand finger balance. However, Ramsey has also found that a centered left-hand frame is a fundamental part of good viola technique. To build this frame, she recommends the practice of double stops such as thirds and octaves as a part of the warm-up routine as discussed previously. ${ }^{139}$ The fingers of the left hand must cooperate to create a consistent hand frame that permits the execution of double stops.

\section{How to Practice Vibrato}

One of the advantages of integrating the "Coordination" technique into viola playing is the ability to synchronize both arms. After breathing out while approaching the string from both ends, the left hand is free to vibrate through the "Plop" concept. To develop and maintain the vibrato, Ramsey uses a three-step exercise that has served to find the most natural motion for the left hand. The player starts by situating the hand in first position on any given string and plays an ascending scale of four eighth notes to a down-bow and then a descending scale of four eight notes to an up-bow, without vibrating and while keeping the left thumb relaxed. The fingering required for this exercise should be 1-2-3-4 to ascend on the down-bow and 4-3-2-1 to descend on the up-bow. Each note should be an eighth note at a tempo of 60 beats per minute. In between each pair of notes, there should be an eight-note rest that will be used to release the hand back with an active "Jerk." The finger that is dropped on the fingerboard is raised vertically from the

\footnotetext{
${ }^{139}$ Ramsey interview.
} 
base knuckle until it reaches an unconstrained position. Depending on the shape of the player's hand, the angle between the fingertip of the finger dropped and the base knuckle might differ. By adding this release to the dropped finger, it helps prepare the hand for the next finger dropped on the fingerboard. The following numbers correspond to each dropped finger, and the "ANDs" refer to the active release of the hand: "1, AND 2, AND 3, AND 4."

The second part of this exercise adds two small shakes or "Wiggles" to the fingers one finger at a time, which resembles a slow-motion vibrato. In the example "1, AND 2, AND 3, AND, Wiggle, Wiggle," the third finger adds two shakes or "Wiggles," each one being two sixteenth notes long. To help clarify this step, Figure 20 shows the second part of this exercise in measure 3 and 4, and the shakes or "Wiggles" are represented by four sixteenth-notes slurred. This motion should come from the left hand without adding any additional portato motion from the right arm.

Finally, the third part of the exercise requires two "Wiggles" and a glissando upwards and downwards on one note, still using the same tempo. An example of this exercise is shown in measure 5 of Figure 20, and it would call for: "Wig-gle, Wig-gle, Gliss." The "Wiggles" should last two eighth notes each, and the glissando is not meant to reach a specific pitch or to be played on any specific speed. What is important about the glissando is to feel the freedom of moving the finger along the fingerboard, which helps to reduce stiffness while vibrating. This exercise is meant to help students find a natural balance of each finger in the left hand through exaggerating the motion of each finger. ${ }^{140}$

\footnotetext{
${ }^{140}$ Ramsey interview.
} 


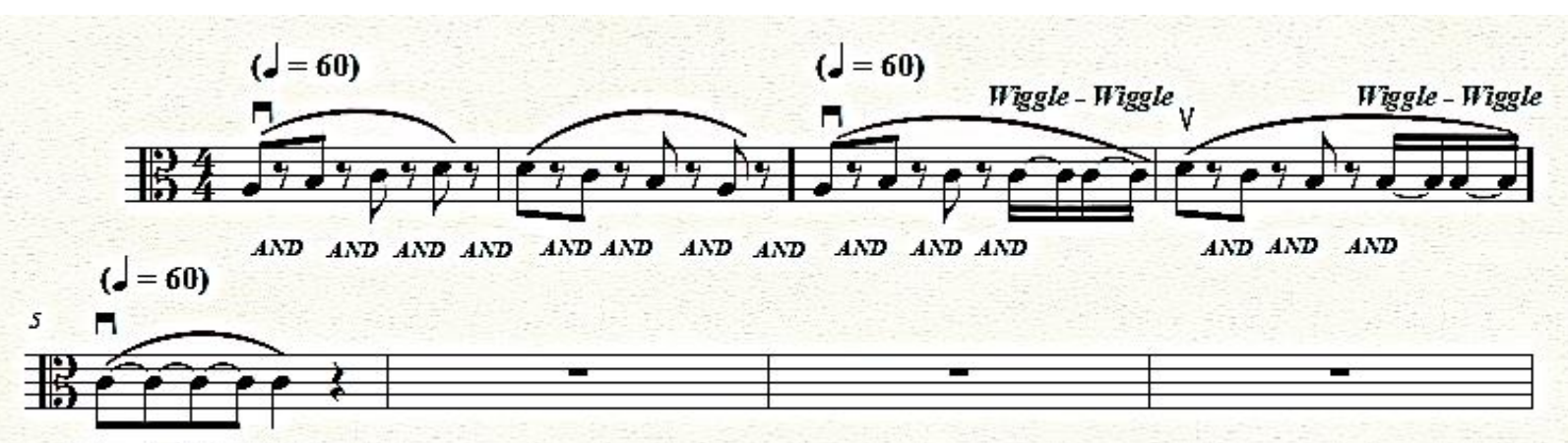

Hig-gle Hig gle Gliss.

Figure 20. Three-Steps Vibrato Exercise Recommended by Ramsey

\section{Recommendation for Shifting Positions}

Ramsey teaches shifting in way designed to connect both notes as much as possible. In one demonstration, she shifts from an E, first finger, first position, on the D string, to the B, third finger, third position on the same string. Ramsey recommends practicing the shift slowly and with a glissando. Before shifting, she suggests players add a small bounce backwards away from the torso in the left elbow. This motion is transferred to the wrist, which also bounces back and helps release part of the weight of the dropped finger without lifting the finger from the fingerboard completely. This release of the weight from the finger provides a smooth preparation to the glissando motion and the bouncing motion of the elbow provides an advantage similar to bending the knees prior to jumping. After the first finger is partially released from the fingerboard, the hand shifts with a slow glissando. The right arm and the left hand must be coordinated. This coordination is obtained by combining a heavier bow during the shift and by reducing the speed of the shift. Once the hand reaches third position, the player drops their third finger on the string, depressing it to the fingerboard, and then releases its weight off the fingerboard. Ramsey recommends that players use the "Plop and Slur" technique in combination 
with working through the etude book Change of Positions, op. 8 by Ševčík. ${ }^{141}$ Ramsey’s shifting technique shows that a fluid coordination between both arms provides an accurate and efficient shift.

\section{A Guide to Phrasing}

To complement this overview of Ramsey's teaching methodologies, she uses Tuttle's "Sheet of Emotions." Although Tuttle originally created this document, Ramsey refers to it when a student needs musical guidance. ${ }^{142}$ Each adjective found in this table is organized into five categories that correspond to five basic emotions: love, joy, anger, fear, and sorrow. A violist can musically evoke any of these emotions by altering some of the playing variables, such as vibrato, bow-weight, contact point, or bow-speed. For instance, this grid might be useful while preparing an excerpt list for an audition if any excerpts lacked musical direction. By using this grid, the performer could find an appropriate emotional context for the excerpt, which will provide the fitting amount of vibrato, bow-speed, bow-weight, and contact point. This combination of these performance parameters helps the performer develop the musical line to convey the appropriate emotion for the piece.

\footnotetext{
${ }^{141}$ Ramsey interview.

142 Ibid.
} 
Table 2. "Sheet of Emotions" Prepared by Tuttle and Taught by Ramsey

\begin{tabular}{|c|c|c|c|c|}
\hline LOVE & JOY & ANGER & FEAR & SORROW \\
\hline Lust & Frank & \begin{tabular}{|l} 
Torment \\
\end{tabular} & Torment & Tragic \\
\hline Longing & Rollick & Morose & Urgent & Torment \\
\hline Flirt & Capricious & Stormy & Anxious & Sad \\
\hline Amiable & Naive & Frenzy & Ominous & Longing \\
\hline Nostalgia & Peaceful & Complain & Shock & Stark \\
\hline Languor & Tickle & Agitated & Agitated & Cry \\
\hline Tender & Boisterous & Kvetch & Mystery & Supplicant \\
\hline Tease & Inner Joy & Rage & Ghostly & Despair \\
\hline Abandon & Luminous & Snarl & Evil & Doldrums \\
\hline Quiet & Whimsy & Madness & Pain & Plead \\
\hline Passion & Exaltation & Frustrated & Beg & Wail \\
\hline Sentimental & Ecstatic & Crouch & Timid & Shriek \\
\hline Forthright & Mischief & Fury & Apprehension & Heartbreak \\
\hline Noble & Gay & Sarcastic & Suspense & Lost \\
\hline Majestic & Buoyant & Grim & Terror & Bleak \\
\hline Cry & Twinkle & Tortured & Awe & Pensive \\
\hline Plead & Spritely & Anguish & Reverence & Yearning \\
\hline Supplicant & Vigor & Irritated & Uneasy & Agony \\
\hline Frolic & Comic & Violent & Depressed & Melancholy \\
\hline \multirow[t]{8}{*}{ Innocent } & Sassy & Vehement & Panic & Tortured \\
\hline & Caricature & Fierce & Cold & Death Toll Bell \\
\hline & Frolic & Restless & Startled & Passion \\
\hline & Effusive & Crochety & Ophelia & Noble \\
\hline & Buffoon & Crank & Insane & Prayer \\
\hline & Mimic & Hate & Eerie & Stagnant \\
\hline & Elegant & Peevish & Grind & \\
\hline & Wonder & & & \\
\hline
\end{tabular}


This chapter aims to share the main techniques that Ramsey teaches to her students. The author does not intend to offer a complete compilation of her teaching methods, but instead, to create a list of the techniques that Ramsey emphasizes as a teacher. The next chapter provides career advice and other material Ramsey has shared with her students. 


\section{CHAPTER 4}

\section{CAREER ADVICE FOR THE UPCOMING PROFESSIONAL VIOLIST}

This chapter includes a variety of topics such as the misconception of talent, career choices, choosing an instrument, and other recommendations from Ramsey. The last chapter focuses on topics of the interest of viola students and professional violists who seek for additional guidance through their careers.

\section{The Misconception of Talent}

When I asked Ramsey about the importance of talent in being successful, she responded, "the harder I work, the more talented I can be." After a long and fruitful career as a performer and teacher, Ramsey offered her point of view on the most important factors that influence the career of a violist. If a viola student is rejected following an entrance audition for a music school, this might erode the confidence of the player in the long run. Similarly, a professional violist might rethink whether their chosen career path is viable if they are constantly rejected from orchestra auditions or college faculty positions. When these unfortunate events happen, the violist might believe that they are not talented enough to compete in the current job market. Ramsey states that a certain amount of innate talent is needed to succeed, but that talent is not a guarantee of success. For her, the only way to find success is by maintaining a diligent work ethic and attention to detail. However, diligent work without clear intentions can be counterproductive so she advises that having a constant practice routine that reviews the performance skills found in the "Performance Pillars" might impact in the outcome of a successful career in music. ${ }^{143}$

\footnotetext{
${ }^{143}$ Ramsey interview.
} 
While growing up, Ramsey developed a meticulous practice routine and scrupulous attention to detail, and this offered her the opportunity to dedicate her life to her passion. She also realized that if practice was treated as an obligation, it would eventually lose its purpose. For that reason, players should have an internal drive that motivates them to practice constantly in order to consistently give the best representation of themselves that they can and to be able to compete in a very demanding market.

An upcoming violist also needs to take into consideration the difficulties found along their musical path that might cause the transition between being a student and becoming a professional to be a challenge. For example, students and professionals face constant exposure to criticism that might play a part in causing stage fright. Several factors helped Ramsey to manage stage fright differently from other musicians, including frequent relocations and the need to her to quickly fit in in new situations. While growing up, her father was in the navy and the family moved often. This required Ramsey to acquire resilience and strength during stressful moments. Even though this helped her to reduce her stage fright levels, she was also always as prepared as possible to avoid a lack of confidence while performing. ${ }^{144}$

\section{The Instrument Factor}

Instruments can influence musicians' careers. Ramsey describes her own experience with different instruments: until recently, she had been playing an instrument made by Helmuth A. Keller ${ }^{145}$ which offered a dark and mellow sound to her playing. But when she suffered an injury involving her left shoulder, the dimensions of her instrument made it difficult for her to continue

\footnotetext{
144 Ibid.

145 “Helmuth Keller, Violin Maker," Tarisio Fine Instruments and Bows, Tarisio Auctions, accessed October 16, 2018, https://tarisio.com/cozio-archive/browse-the-archive/makers/maker/?Maker_ID=2363.

This entry shows an auction made in 2012 which sold an instrument made by Keller in 1973. Among other details, it shows illustrations of the instrument, and the body length of the instrument (16 in. 1/2). This information also serves to compare Ramsey's previous instrument made by Keller to the instrument offered at the auction. Ramsey's instrument had a body length of 17 in. $1 / 4$.
} 
to play it. As a short-term solution, she decided to borrow a smaller viola, owned by her

daughter. Even though the quality of this instrument was not that of her previous instrument, she received positive feedback regarding its powerful projection and clarity. Soon after, Gabrielle Kundert ${ }^{146}$ made an instrument of higher quality and similar proportions to Ramsey's daughter's, and Ramsey decided to acquire it and use it. After a short period adjusting to the viola made by Kundert, Ramsey and her quartet recorded a concert, and to her surprise, this new instrument offered similar qualities compared to her Keller, including better projection. ${ }^{147}$ Even though the two instruments have different dimensions and qualities, Ramsey realized that violists themselves provides a noticeable contribution to the sound quality of any instrument. After sharing the stage with many successful musicians throughout her career, Ramsey has observed some string musicians trying to improve their performance qualities by acquiring instruments of higher value compared to their previous instruments. Unfortunately, these musicians were not able to improve their sound qualities in their newly acquired instruments. Consequently, Ramsey believes that an expensive instrument is not a decisive factor for a successful viola career, but that the performer's own qualities are far more significant.

\section{Recommended Repertoire and Etudes to Learn as a Student}

The students who study with Ramsey at the Cleveland Institute of Music are usually pursuing a graduate degree in viola performance with professional goals such as joining an orchestra, playing chamber music, or a having a teaching career. (Ramsey does not consider herself to be a specialist in historical performances and she prefers that her students learn about

\footnotetext{
146 “Gabrielle Kundert,” Biography, accessed October 15, 2018, http://www.kundertviolas.com/index.php/bio. This entry shows a list of some of the violist that acquired an instrument made by Kundert. Among other successful violist, the list includes names such as, Roberto Diaz (former principal of the Philadelphia Orchestra), Helen Callus, (viola professor at the Bienen School of Music at Northwestern University), and James Dunham (former violist of the Cleveland Quartet).

${ }^{147}$ Ramsey interview.
} 
these traits with specialists on the matter.) While choosing repertoire for her students, Ramsey focuses on finding and assigning pieces that will enhance her students' performance abilities, such as intonation or phrasing.

Ramsey regularly teaches the Six Suites for Solo Violoncello, BWV 1007-1012 by J. S. Bach, which are especially valuable for teaching double stop accuracy. She also recommends the E-flat Major and F Minor Viola Sonatas by Brahms. She teaches a number of concertos, including Mozart's Sinfonia Concertante for Violin and Viola in E-Flat Major, K. 364 (320d); Bloch's Suite, B.41, (1919) for Viola and Orchestra; and viola concertos by Béla Bartók, William Walton, and Paul Hindemith. She recommends that students learn György Ligeti’s viola sonata to strengthen phrasing ideas and Zoltan Kodaly's “Adagio," in which students learn how to sustain the bow in slow passages. Ramsey often teaches Britten's Lachrymae: Reflections on a Song of Dowland, for viola and piano, Op. 48; Kenji Bunch's 3G's, which requires sound amplification and scordatura; and other pieces with unusual instrumentation or other demands. Ramsey recommends technique books by Gaviniès, Kreutzer and Ševčík. ${ }^{148}$ Most of the pieces taught by Ramsey are well-known by the viola community, and she admits that she teaches some of these pieces only because she enjoys them. Most importantly, for Ramsey, the viola pieces she picks for her students serve as the vehicles to transmit her ideas about viola playing, and she notes that her techniques can be applied to the entire viola repertory.

\section{Comments about Her Chamber Music Collaborations}

Chamber music has played a strong part in Ramsey's life as a performer, and her varied collaborations have enriched her overall experience as a violist. In the chamber music setting, the interactions within the group are more personal than as a member in an orchestra; this offers both advantages and disadvantages to the performance experience. Ramsey has noticed that after

\footnotetext{
${ }^{148}$ Ramsey interview.
} 
playing with the Amici String Quartet, she is more creative with her musical phrasing, and increasingly aware of the ending of notes. Chamber music has sharpened her ears while listening to the other instruments in orchestra. ${ }^{149}$ During Ramsey's six years as a member of the Panorámicos ensemble, she found joy in performing new repertoire and performing alongside with life-long colleagues but performing with this group also presented some challenges. As a methodical performer, she did not always fully agree with how the group's recording processes took place. Some of these recordings were not performed in public prior to the recording, which to Ramsey seemed to create an artificial version of some of the pieces. A recording project that Ramsey found more enjoyable was with flutist Michelle Dubost and violinist Takako Masame in which the ensemble played several performances prior to the recording, offering a more authentic final product for Ramsey.

\section{$\underline{\text { 5. Career Choices and Alternate Paths of Ramsey's Former Students }}$}

Ramsey usually trains violists to become orchestra players, but some of her students have taken different career routes. These include playing as a member of string quartets, ${ }^{150}$ faculty positions in universities, ${ }^{151}$ as a part of large education systems, ${ }^{152}$ or as arts administrators. ${ }^{153}$

Besides these professional paths, some of her students have continued their education by

${ }^{149}$ Ibid.

150 “Eric Wong, Viola," biography, Cavani String Quartet, accessed October 16, 2018, http://cavanistringquartet.com/aboutus/eric-wong/.

This entry shares a biographical description of the violist, Eric Wong who joined the Cavani String Quartet after its previous violist, Kristen Docter joined the faculty at the Oberlin Conservatory, in 2016.

${ }^{151}$ Erich Burnett, "New Releases: Violist Kirsten Docter '92 to Join Oberlin Conservatory Faculty," New Releases, Oberlin College and Conservatory, February 5, 2016, accessed October 16, 2018,

https://www.oberlin.edu/news/violist-kirsten-docter-92-join-oberlin-conservatory-faculty.

In this article, Erich Burnett describes the new appointment of the violist Kristen Docter, among other details. The article shares that Docter joined the viola faculty at the Oberlin Conservatory in 2016, after 13 years as a member of the Cavani String Quartet.

152 "Catherine Shilling,Viola," biography, Louisiana Philharmonic Orchestra, accessed October 16, 2018, https://lpomusic.com/Education/Online/loadArticle.asp?BOparam::WScontent::loadArticle::article_id=9584070D94E8-4D26-88F0-7F9AF49A628D.

This entry shares a biographical description of the violist, Catherine Shilling. Among other details, this biography adds that Shilling teaches for "El Sistema-inspired programs" in New Orleans, where she currently resides.

${ }^{153}$ Ramsey interview. A former student of Ramsey joined the Development Department of the Cleveland Orchestra. 
specializing in a field of study through doctoral degrees or orchestral training programs. Before one of her students decides to follow any of these paths, Ramsey recommends evaluating the possible consequences cautiously. For example, if a student is interested in teaching viola at a college position, the doctoral degree is usually required. By pursuing this degree, the student is usually involved in time-consuming curricular requirements that might affect their practice routine, and that might reduce their progress as performers when compared to other violists that did not pursue a doctoral degree. Ramsey understands, however, that if a student is interested in teaching in college, the doctoral degree is a necessary choice. Some of her students have also participated in orchestral training programs, such as the New World Symphony. ${ }^{154}$ Once they have won a position in a training orchestra, players join a high-level orchestra formed by young professionals. If a student is interested in joining an orchestral training program, Ramsey supports their decision, but she does not believe it is a choice for everyone. She observed that some students stopped their meticulous and invested practice routines while being a member of these programs, and this possibility should be taken into consideration when students are offered opportunities in training orchestras.

\section{A Final Word About Orchestral Auditions}

If a violist chooses the path to become a full-time orchestra member, one obstacle to achieving that goal is the increasing number of highly qualified violists. One of the reasons of the current increase in highly qualified violists auditioning might be due to the benefits of joining an orchestra. For instance, the base salary for the top ten orchestras in the US during the 20142015 season was above hundred thousand dollars. ${ }^{155}$ To deal with this market, Ramsey offers advice to violists auditioning for major orchestras to overcome a sense of failure. For her, "the

\footnotetext{
154 “About the New World," New World Symphony, accessed October 16, 2018, https://www.nws.edu/.

155 Julia Hatmaker, "These Are the 13 Highest Paid Orchestras in the United States," Penn Live, October 3, 2016, accessed December 1, 2018, https://www.pennlive.com/life/2016/10/highest_paid_orchestras.html.
} 
thing ... to remember ... is that you can only play the way you play." ${ }^{156}$ She claims that during the audition, you can aim for consistent intonation, clarity of articulation, and accurate rhythm, but the feedback from the committee may give two opposite opinions about your playing. She says that the only route to success in an orchestral audition is to be overly prepared. This means to control every "Performance Pillar," while having a good sense of musical line and musicianship. If that is not good enough to win a job, players should ask for feedback from the committee members and then review those for the next audition. Ramsey also recommends a brief pause between auditions to start the whole preparation process over. Furthermore, she believes that musicians nowadays tend to play at a higher level than in past generations, with a standardized approach to intonation and sound quality. Ramsey also notes that many musicians are trying to find different career paths than did previous generations. This change of goals might differ as compared to her own experience in her career, but she tells her students that finding career success "depends on what might make them happy in their music-making." 157

\section{A Final Word about the Future of the Orchestras in the US}

Ramsey has played in orchestras for her entire professional career. This allows her to have a credible opinion about the future of this type of ensemble. Over the years, she has seen some orchestras go on long strikes, such as the Minnesota Orchestra (2012 - 2014). Some of these ensembles left these challenging times behind and resumed their usual performance schedule. Other orchestras have greatly flourished, such as the Pittsburgh Symphony which added their first summer season in $1975 .{ }^{158}$ Over time, social fluctuations brought stability to some ensembles and challenges to others. In Ramsey's opinion, most orchestras in the US will manage to stay afloat. Moreover, she states that the Cleveland Orchestra is a very good example

\footnotetext{
${ }^{156}$ Ramsey interview.

157 Ibid.

158 Ibid.
} 
of how orchestras must adapt to new audiences. Its members are engaging with the audience more than ever, and the community response has been positive. In 2010, the Maltz Family Foundation of the Jewish Federation made a $\$ 20$ million donation to the orchestra to create the Center for Future Audiences. ${ }^{159}$ This made it possible for younger audiences to attend the orchestra's concerts almost free of charge. The Orchestra received another generous donation with similar purposes in 2017, the "largest single gift ever and the second largest gift to the orchestra in recent history." 160 These endowments have brought the youngest audience in the country to the Cleveland Orchestra and, with it, a promising future. ${ }^{161}$

${ }^{159}$ Zachary Lewis, "Maltz Family Foundation Makes \$20 million Gift to Cleveland Orchestra," The Cleveland Plain Dealer, October 26, 2010, https://www.cleveland.com/musicdance/index.ssf/2010/10/maltz family foundation makes.html. ${ }_{160}$ Zachary Lewis, "Richard and Emily Smucker Pledge \$15 Million to Cleveland Orchestra," The Cleveland Plain Dealer, November 8, 2017, https://www.cleveland.com/musicdance/index.ssf/2017/11/richard_and_emily_smucker_pled.html. ${ }^{161}$ Ramsey interview. 


\section{CONCLUSIONS}

The main purpose of this document is to share as much information as possible about the career and teaching methods of Lynne Ramsey. This has been very valuable to me because I could study the career of a mentor who has been important to my viola education. Ramsey's attitudes changed my perspective on viola performance during my time as a viola student at the Cleveland Institute of Music, and I would venture to say that Lynne Ramsey and, of course, Jeffrey Irvine, who was my primary teacher at CIM, were as inspiring to me as Tuttle was to them. Ramsey describes Tuttle as a teacher who found that "special nugget or kernel" in every student, and then figured out a way to develop them. ${ }^{162}$ I experienced this myself as a student of both Ramsey and Irvine.

Ramsey's musical career was full of challenges, and maybe due to this struggle, her success is even more pronounced. In my first chapter, I mention that some of Ramsey's teachers were not the right fit for her, which forced her to seek other institutions and teachers elsewhere. Fortunately, Ramon Scavelli and Karen Tuttle believed in her, and their contributions to Ramsey's development as a musician were vital. Moreover, Tuttle's techniques aimed to improve the playing skills of a violist, and more specifically, the skills needed for a chamber music setting, as Sophie Elizabeth Parker states in her dissertation. Parker's dissertation includes a survey of viola teachers and their teaching methods, and her study shows that Tuttle is considered, along with Heidi Castleman and Robert Vernon, as one of the most influential viola mentors in the $20^{\text {th }}$ Century in the U.S. Furthermore, Parker states that, "[t]he Tuttle school include[s] [...] [Tuttle's former] pupils such as Karen Ritscher and Kim Kashkashian, who continue the teachings of the Coordination Method, and represent teaching more from a chamber

\footnotetext{
${ }^{162}$ Ramsey interview.
} 
music infused background." ${ }^{163}$ Among other important qualities, Tuttle's teaching techniques aim to improve chamber music skills by creating connections between pieces and players through exercises such as the "Sheet of Emotions." Also, by incorporating a natural breathing into playing with techniques such as the "Initiators," the player is able to better synchronize with the other members of the chamber ensemble. This type of background greatly improved Ramsey's viola technique and expressiveness, which, among other successes, allowed her to perform in chamber music settings with renowned chamber players including harpist Ursula Holliger and flutist Michelle Dubost. Most importantly, Ramsey's career goals have always been to be part of a large ensemble, and after studying with Tuttle, she managed to transfer Tuttle's instructions into orchestral playing. For that reason, her success as a "Tuttle's orchestral player" has been highly regarded in the viola community. As a violist, she found a way to combine both worlds in one, and this allowed her to continue using Tuttle's technique while enjoying a highlevel orchestral career. Even though her career path was always to become an orchestral violist, her major influences while a student were not orchestral specialists such as Robert Vernon or Joseph de Pasquale, and for that reason, her career path offers a unique perspective about viola playing.

As a professional musician, Ramsey had to deal with bias in orchestral ensembles mostly formed by male musicians. Sexism put Ramsey at a disadvantage, and she had to be overprepared to demonstrate an even higher level of viola playing than many thought possible to win an orchestral job. Her flexibility and drive during her career have contributed to her teaching style, and she is very supportive and encouraging of her students. In my own experience, Ramsey promoted these values as a teacher, and I plan to instill them in my future students as well. Ramsey's teaching goal, to promote a viola technique that allows her students to perform in a 163 Parker, “A Survey of Viola Teachers' Perceptions,” 129. 
methodical and simplified way, is a method many can use to teach. For instance, by introducing analogies or songs learned during childhood she teaches the basics of the right-arm motion. This reduces the quantity of words needed to instruct her students, while still communicating her message. Ramsey has also provided great insights related to career advice. Some of the most useful pieces of information that I found while preparing this document were related to the misconception of talent. She is the living example that proves that hard work and being passionate about achieving your dreams can provide positive results. Her opinion about the future of professional violists opens new possibilities to the upcoming generations. Traditionally, and according to Ramsey, the orchestral path was the ultimate goal for violists, but now Ramsey is aware that this might change in the future. For me, preparing this research document has been a very valuable opportunity since I was able to explore another career path than orchestral auditions. This self-discovery has been a very important event in my career as a violist, and for that I am very grateful. It is my hope that this research project will be as useful to other violists as it has been to me. 


\section{BIBLIOGRAPHY}

\section{Interviews}

Ramsey, Lynne. Interview with author. April 2018.

Scavelli, Ramon. Interview with author. May 2018.

\section{Dissertations}

Burns, Lauren. "Coordinated Action in String Playing: A Comparative Study of the Teachings of Paul Rolland and Karen Tuttle.” DMA document, University of Alabama, 2013.

Chien, Shao-Chin. "Application of the Principles of the Alexander Technique to Viola Playing and Performance." DMA document, University of Miami, 2007.

Dane, Matthew. "Coordinated Effort: A Study of Karen Tuttle's Influence on Modern Viola Teaching.” DMA document, Rice University, 2002.

Dubois, Susan L. "Current Methods and Techniques in College-Level Viola Pedagogy.” DMA document, Julliard School of Music, 1996.

Jensenius, Emily. “An Annotated Bibliography of Selected Viola Works for Pedagogy of Contemporary Music Styles and Techniques.” DMA document, Florida State University, 2014.

Kella, John Jake. "The Development and Qualitative Evaluation of a Comprehensive Music Curriculum for Viola, with an Historical Survey of Violin and Viola Instructional Literature from the $16^{\text {th }}$ Through $20^{\text {th }}$ Centuries, Including a Review of the Teaching Concepts of William Lincer." PhD diss., New York University, 1983.

Liao, Chien-Ju. "Excerpts for Viola: An Alternative Pedagogical Method for the Aspiring Orchestral Violist.” DMA document, University of Cincinnati, 2009.

Neubert, Peter. "The Development of Viola Instruction at the Paris Conservatoire during the Nineteenth Century and the Evolution of an Idiomatic Style of Writing for the Viola as seen through the Music of the Viola Concours, 1896-1918." DMA document, University of Kentucky, 2004.

Parker, Sophie Elizabeth. “A Survey of Viola Teachers' Perceptions of Viola Pedagogy.” DMA diss., University of Houston, 2014.

Rose, Christopher. "An Orchestra Audition Preparation Handbook for Bass Players.” Research paper, Arizona State University, 2011.

Salinas, Ashley D. “Original Viola Study Literature: Analyzing the Pedagogical Contributions of Marco Frank.” DMA document, University of North Texas, 2018. 
Warmath, Jordan. "The Contemporary Revolution-Evolution of Viola Repertoire.” DMA document, University of California, Santa Barbara, 2017.

Wetzel, Minor Lewis. “A Better Bartók-Dilemmas and Solutions in Performing Bartók's Viola Concerto.” DMA document, University of California, Los Angeles, 2010.

\section{Websites and Journals}

Anderson, George. "Triangle Tattler: Maguire on Broadway, Townfolk.” Pittsburgh PostGazette. January 29, 1980: 37. https://search-proquestcom.www.libproxy.wvu.edu/hnppittsburghpostgazette/docview/1859679924/8DA833D4088449 $\underline{5 \mathrm{FPQ} / 10 ? \text { accountid=2837. }}$.

American Viola Society. "2014 American Viola Society Awards Announcement: Maurice W. Riley Award." Accessed August 18, 2018. http://studio.americanviolasociety.org/blog/2014/06/american-viola-society-awardsannouncement/.

Beeching, Angela Myles. "Resources: Orchestral Opportunities.” Accessed July 6, 2018. http://global.oup.com/us/companion.websites/9780195382594/resources/resource16/.

Boerner, Henri. "American Airlines Sponsored the American Youth Performs Program.” March 8, 1971. https://hankboerner.com/biography/careerarchives/AA\%20\%20American\%20Youth\%20Performs\%2003-08-71.pdf.

Burnett, Erich. "New Releases: Violist Kirsten Docter '92 to Join Oberlin Conservatory Faculty." Oberlin College and Conservatory. February 5, 2016, accessed October 16, 2018. https://www.oberlin.edu/news/violist-kirsten-docter-92-join-oberlin-conservatory-faculty.

Claisse, Melissa. "The Pièces de Concours: Rediscovered Treasures from Turn-of-the-Century France: A Conversation with Violist Jutta Puchhammer-Sédillot." Journal of the American Viola Society, With Viola in Hand, vol. 33, (Summer 2017): 43. https://www.americanviolasociety.org/DownloadFile.php?FN=JAVS-Summer-2017.pdf.

Cavani String Quartet. “Eric Wong, Viola.” Biography. Accessed October 16, 2018. http://cavanistringquartet.com/aboutus/eric-wong/.

Cleveland Arts Prize. "2011 Lifetime Achievement Award for Music and Dance: David Cerone." Accessed August 18, 2018. http://clevelandartsprize.org/awardees/david_cerone.html.

ClevelandClassical.com. "Arts Renaissance Tremont: Amici String Quartet Performance." Accessed August 19, 2018. https://clevelandclassical.com/arts-renaissance-tremont-amici-stringquartet-february-15/.

Cleveland Institute of Music. "String Faculty: Lynne Ramsey." Last modified August 20, 2013. http://archive.li/Optpg. 
Cummings, Robert. "Michael Debost: Biography." AllMusic. Accessed August 20, 2018. https://www.allmusic.com/artist/michel-debost-mn0000070348/biography.

Erin Arts Center. " $13^{\text {th }}$ Lionel Tertis Viola Festival and Competition: Information Booklet." Accessed August 12, 2018. https://www.erinartscentre.com/assets/pdfs/TertisBooklet.pdf.

Fuld, James J. "Patriotic Music: After 1865." Grove Music Online. Accessed August 15, 2018. https://doi-org.www.libproxy.wvu.edu/10.1093/gmo/9781561592630.article.A2225007.

Goodwin, Noël. "Pinchas Zukerman.” Grove Music Online. Accessed August 15, 2018. https://doi-org.www.libproxy.wvu.edu/10.1093/gmo/9781561592630.article.31057.

Hatmaker, Julia. "These Are the 13 Highest Paid Orchestras in the United States." Penn Live. October 03, 2016. Accessed December 1, 2018. https://www.pennlive.com/life/2016/10/highest_paid_orchestras.html.

Henahan, Donal. "Music: St. Paul Orchestra.” The New York Times. November 4, 1987: 22. https://www.nytimes.com/1987/11/04/arts/music-st-paul-orchestra.html.

Interlochen Center of the Arts. "Interlochen Viola Institute: Lynne Ramsey." Accessed August 16, 2018. http://camp.interlochen.org/person/lynne-ramsey.

Journal of the American Viola Society. "Oberlin Conservatory of Music: Viola Faculty." Vol. 2, no. 3, November, 1986: 4. http://www.americanviolasociety.org/PDFs/Journal/JAVS-2 3.pdf.

Jander, Owen, and Ellen T. Harris. "Son Filé." Grove Music Online. Accessed June 11, 2018. https://doi-org.www.libproxy.wvu.edu/10.1093/gmo/9781561592630.article.26206.

Lewis, Zachary. "Maltz Family Foundation Makes \$20 million Gift to Cleveland Orchestra." The Cleveland Plain Dealer. October 26, 2010, https://www.cleveland.com/musicdance/index.ssf/2010/10/maltz_family_foundation_makes.html

Lewis, Zachary. "Richard and Emily Smucker Pledge \$15 Million to Cleveland Orchestra." The Cleveland Plain Dealer. November 8, 2017.

https://www.cleveland.com/musicdance/index.ssf/2017/11/richard_and_emily_smucker_pled.ht $\underline{\mathrm{ml}}$.

Library of Congress. "Foundations for Music: Elizabeth Sprague Coolidge." Accessed August 9, 2018. https://www.loc.gov/rr/perform/guide/fndmus.html.

Louisiana Philharmonic Orchestra. "Catherine Shilling, Viola." Biography. Accessed October 16, 2018. https://lpomusic.com/Education/Online/loadArticle.asp?BOparam::WScontent::loadArticle::artic le_id=9584070D-94E8-4D26-88F0-7F9AF49A628D. 
Magg, Fritz. "Bloomington Faculty Council Minutes: Memorial Resolution for David P. Dawson.” Indiana University. April 6, 1976.

http://webapp1.dlib.indiana.edu/bfc/view?docId=B34-1976.

McGegan, Nicholas. "Nicholas McGegan: Biography.” Accessed September 18, 2018. http://nicholasmcgegan.com/biography/.

Music of the Baroque. "Jane Glover: Biography." Accessed September 18, 2018. https://www.baroque.org/About/Performers/jane-glover.

New World Symphony “About the New World Symphony." Accessed October 16, 2018. https://www.nws.edu/about/about-nws/.

Niles, Laurie. "Playing Viola with Ease: Karen Tuttle's Concept of 'Coordination'." Violinist.com. June 23, 2016. Accessed September 24, 2018. https://www.violinist.com/blog/laurie/20166/19585/.

Pittsburgh Post-Gazette, South Hills Edition. "Going South, in Concert." February 26, 1981. ProQuest, 69. https://search-proquestcom.www.libproxy.wvu.edu/docview/1859941724? accountid=2837.

Pittsburgh Post-Gazette, Weekend Section. "Chamber Music at Heinz Hall, Performance with members of the Pittsburgh Symphony." November 16, 1984. ProQuest, 4. https://searchproquestcom.www.libproxy.wvu.edu/hnppittsburghpostgazette/docview/1860069916/CB88B5BC34CF4 $\underline{\mathrm{DF} 8 \mathrm{PQ} / 2 \text { ?accountid=2837. }}$.

Kundert Violas. “Kundert: Bio.” Biography. Accessed October 15, 2018.

http://www.kundertviolas.com/index.php/bio.

Reiter-Bootiman, Emmanuella. "Karen Tuttle, 1920 - 2010.” The Strad Magazine. Vol. 122, issue 1451, ISSN 0039-2049: 30-31.

http://search.ebscohost.com.www.libproxy.wvu.edu/login.aspx?direct=true $\& d b=f 5 h \& A N=5804$ $\underline{2278 \& \text { site }=\text { ehost-live. }}$.

Rice University, The Shepherd School of Music. "Violin Faculty: Paul Kantor." Accessed August 19, 2018. https://music.rice.edu/faculty/paul-kantor.

Ritscher, Karen. “An Interview with Karen Tuttle.” American String Teacher, vol. 43, no. 4. ISSN: 0003-1313, 14 December, 2017: 89. WorldCat. https://libwvu-on-worldcat-org.www.libproxy.wvu.edu/oclc/7260399753.

Rosenberg, Donald. "Reflections." Review of Panorámicos Ensemble. Cleveland Plain Dealer. December 13, 2009.

http://www.cleveland.com/musicdance/index.ssf/2009/12/classical_cds.html. 
Rosenblum, Myron. "From Discovery to Publication: The Path of 18th-Century Ignatz Gspan's Concerto for Viola and Strings." Journal of the American Viola Society, vol. 18, no. 2 and 3: 77. http://www.americanviolasociety.org/PDFs/Journal/JAVS-18.23.pdf.

Rutledge, Christine. "Orchestral Training Forum: Orchestra Repertoire Lists.” Journal of the American Viola Society, vol. 17, no. 1, spring 2001: 61-65.

https://www.americanviolasociety.org/PDFs/Journal/JAVS-17.1.pdf\#page=62.

Storch, Laila. "Marcel Tabuteau.” Oxford University Press. Accessed October 14, 2018. https://doi-org.www.libproxy.wvu.edu/10.1093/gmo/9781561592630.article.27348.

SunMusic Strings. “Analysis of Carl Flesch Scales System: Scales.” Accessed June 27, 2018. http://beststudentviolins.com/scales.html.

Tarisio Fine Instruments and Bows. "Helmuth Keller, Violin Maker.” Tarisio Auctions. Accessed October 16, 2018.

https://tarisio.com/cozio-archive/browse-the-archive/makers/maker/?Maker_ID=2363.

The Cleveland Orchestra. "From the Archives: About the Archives." Accessed August 16, 2018. https://www.clevelandorchestra.com/from-the-archives/orchestra-archives/.

The Cleveland Orchestra. "About the Orchestra: Mission and History." Accessed August 16, 2018.

https://www.clevelandorchestra.com/about/mission-and-history/.

The Cleveland Orchestra. "Orchestra Members: Lynne Ramsey.” Accessed August 16, 2018. http://www.clevelandorchestra.com/About/Musicians-and-Conductors/Meet-the-Musicians/M-SMusicians/Ramsey-Lynne/.

The William Lincer Foundation.’William Lincer's Biography.” Accessed August 9, 2018. http://www.williamlincer.org/bio.htm.

Ursula Holliger. "Harpist: Ursula Holliger.” REM2. Accessed August 18, 2018. http://www.ursulaholliger.net/index.html.

Vernon, Robert. "Orchestral Training Forum.” Journal of the American Viola Society, vol. 15, no. 3, winter 1999: 38.

https://www.americanviolasociety.org/PDFs/Journal/JAVS-15.3.pdf\#page=34.

World Concert Hall. "Beijing Concert Hall.” Accessed August 14, 2018. https://www.worldconcerthall.com/en/halls/beijing_concert_hall/88/.

Lewis, Zachary. "Cleveland Orchestra Shines Across the Board in Premiere, Schubert's 'Great' Symphony (Review)." The Cleveland Plain Dealer. November 20, 2015.

https://www.cleveland.com/musicdance/index.ssf/2015/11/cleveland_orchestra_shines_acr.html. 
Lewis, Zachary. "Maltz Family Foundation Makes \$20 million Gift to Cleveland Orchestra." The Cleveland Plain Dealer. October 26, 2010.

https://www.cleveland.com/musicdance/index.ssf/2010/10/maltz_family_foundation_makes.html

Lewis, Zachary. "Richard and Emily Smucker Pledge \$15 Million to Cleveland Orchestra." The Cleveland Plain Dealer. November 8, 2017.

https://www.cleveland.com/musicdance/index.ssf/2017/11/richard_and_emily_smucker_pled.ht ml.

\section{Books and Scores}

Beethoven, Ludwig van. Symphony no. 5, in C Minor, op. 67. Edited by Jonathan Del Mar. Kassel, Germany: Bärenreiter, 1999.

Buzeng, Xu. "Jews and The Musical Life of Shanghai." In The Jews of China, edited by Jonathan Goldstein,: 230-231. Armonk, NY: M. E. Sharp, 1999.

Dounis, Demetrios Constantine. The Artist's Technique of Violin Playing: A New Scientific Method for Obtaining, in the Shortest Possible Time, an Absolute Mastery of the Higher Technical Difficulties of the Left Hand and of the Bow, op. 12. New York: Carl Fischer, 1921.

Duport, Jean-Louis. Essai sur le Doigté du Violoncelle et sur la Conduite de L'Archet, 1824.

Flesch, Carl. Scale System. Ed. Charlotte Karman. New York: Carl Fischer, 1942.

Riley, Maurice W. The History of the Viola, 2nd ed. Ann Arbor, MI: Braun-Brumfield, 1991.

Rosenberg, Donald. The Cleveland Orchestra Story: Second to None. Cleveland: Gray \& Co., 2000 .

Ševčík, Otakar. Shifting, Changing the Position, op. 8. Trans. and ed. by Max Aronoff. Bryn Mawr, PA: Elkan-Vogel, 1946.

\section{CD and Video Recordings}

Berlioz, Hector. Harold in Italy. Aspen Concert Orchestra. Paul Vermel. Tent, Aspen Music Festival, Aspen, Colorado. With Lynne Ramsey Irvine, viola. Recorded July 23, 1986. 2 audio discs: digital, $\mathrm{CD}$ audio; 4 3/4 in.

Debost, Michael, flute, Lynne Ramsey, viola, and Takako Masame, violin. Sérénades. BaldwinWallace College Conservatory of Music, Berea, OH: Skarbo, performed February 10, 2008. 1 audio disc: digital, stereo; 4 3/4 in.

Houde, Andrea. The American Viola. Sun Jung Lee, piano. West Virginia University, Morgantown, WV: Albany Records, November 1, 2018. 
Panorámicos Ensemble. Joie de Vivre!. Cleveland, OH: Panorámicos, recorded 2009. 1 audio disc: digital CD audio; 4 3/4 in.

Panorámicos Ensemble. Reflections with Sandra Simon. Cleveland, OH: Panorámicos, recorded 2009. 1 audio disc: digital CD audio; 4 3/4 in.

King, Richard. Chamber Music for Horn. Jesse McCormick, horn, Jung Eun Oh, soprano, JungMin Amy Lee, violin, Mari Sato, violin, Lynne Ramsey, viola, Stanley Konopka, viola, Julie Myers King, cello, Paul Kushious, cello, Orli Shaham, piano. Oberlin OH: Albany Records, 2012, recorded May-June 2011. 1 audio disc: digital, 4 3/4 in.

Vernon, Robert. Orchestral Excerpts for Viola. Tempe: AZ: Summit Records, recorded 1997. 1 audio disc: digital, stereo; 4 3/4 in.

Viola Masterclass: Lynne Ramsey, Viola. Kim, NaYeon, viola, Amy Chiu, piano, Hayaka Komatsu, viola, Keisuke Nakagoshi, piano, Omar Shelly, viola, Deanna Badizadegan, viola. San Francisco Conservatory of Music, Music Library: Concert Hall, recorded, April 14, 2012.2 videodiscs: sd. col.; 4 3/4 in. MPEG video, 2 hr., 11 min. 